\title{
LA CONTAMINACIÓN ATMOSFÉRICAY SU IMPACTO SOBRE LAS ACTIVIDADES TURÍSTICAS, EN MADRID ${ }^{1}$
}

\author{
María Sotelo Pérez \\ Universidad Rey Juan Carlos. Madrid \\ https://orcid.org/0000-0002-5541-7941 \\ José Antonio Sotelo Navalpotro \\ Universidad Complutense de Madrid \\ https://orcid.org/0000-0003-2800-6677
}

\section{RESUMEN}

La contaminación atmosférica, caracterizada por la presencia en la atmósfera de uno o varios elementos contaminantes como gases, humos o polvo, inciden y repercuten de manera directa e indirecta sobre la salud humana y sobre las flora y la fauna -así como en el desarrollo de sus actividades- de un territorio tan amplio, variado y diverso como es la Comunidad de Madrid, lo que se presenta como un factor de riesgo potencial, principalmente, para actividades tan sensibles como las relacionadas con el turismo. Por lo que, a la hora de tratar una temática tan compleja, a la par que diversa, como son los riesgos antrópicos, en relación con las actividades turísticas, se pone de manifiesto la existencia de una problemática igual de importante como es la falta de conocimiento real de los riesgos latentes y presentes en cada uno de los municipios que conforman la Comunidad de Madrid, amén de repercutir considerablemente en la exposición de la población a riesgos de los que carece de información.

Palabras clave: Contaminación atmosférica; impactos ambientales; actividades turísticas.

Fecha de recepción: 14 de mayo de 2018

Fecha de aceptación: 28 de enero de 2019

* Área de Geografía Humana. Facultad de Ciencias Jurídicas y Sociales. Universidad Rey Juan Carlos. Paseo Artilleros, s/n 28032 MADRID (España).E-mail: maria.sotelo.perez@urjc.es

** Instituto Universitario de Ciencias Ambientales. Universidad Complutense de Madrid. C/ Manuel Bartolomé Cossío, s/n. Ciudad Universitaria. 28040 MADRID (España).E-mail: jasotelo@ucm.es

1 La presente investigación se enmarca en el proyecto de investigación SANTANDER-UCM (2018). PR75/18-21573. 


\title{
Atmospheric pollution and its impact on tourist activities, in Madrid
}

\begin{abstract}
Air pollution characterized by the presence in the atmosphere of one or several pollutants such as gases, fumes or dust, impact directly and indirectly on human health and on flora and fauna -as well as in the development of its activities- of such a wide, varied and diverse territory as the Community of Madrid, what is presented as a potential risk factor, mainly, for activities as sensitive as those related to tourism. Therefore, when dealing with such a complex issue, at the same time as diverse, such as anthropic risks, in relation to tourism activities, the existence of an equally important problem such as the lack of real knowledge of the latent and present risks in each of the municipalities that make up the Community of Madrid, in addition to having a considerable impact on the exposure of the population to risks for which it lacks information.
\end{abstract}

Keywords: Atmospheric pollution; environmental impacts; tourist activities.

\section{INTRODUCCIÓN}

En la Comunidad de Madrid, como en el resto del territorio español, los procesos de industrialización y urbanización de grandes áreas territoriales han ido deteriorando la calidad del aire, particularmente en los núcleos urbanos, lo que hace indispensable reforzar la capacidad de acción frente a la contaminación atmosférica ${ }^{2}$. Y, es que, la calidad del aire no sólo constituye una prioridad de la política ambiental, dadas sus repercusiones sobre la salud humana y el medio ambiente, sino que también resulta un aspecto clave para la sostenibilidad, pues la contaminación atmosférica ${ }^{3}$ es un problema local y transfronterizo, provocado por diversos contaminantes y con efectos perjudiciales para el medio ambiente y la calidad de vida de las personas.

Para los profesores Santos-Lacueva, R., Anton Clavé, S y Saladié, O., resulta obvio que para garantizar la sostenibilidad futura del turismo español de sol y playa, en general, y el de interior, en particular, como actividad estratégica, es necesario afrontar algunos de los problemas que acarrea desde sus inicios su relación con el medio ambiente. Son los ligados, principalmente, a la concentración espacial y temporal, a la sobreocupación y a la masificación y abaratamiento de la oferta, que afectan principalmente la calidad de los recursos que fundamentan la actividad turística, desde el agua del mar y las playas, al paisaje, a las actividades relacionadas con el mundo urbano. Problemas, directamente vinculados a los resultados económicos y empresariales de la actividad. Además, en el contexto globalizado

2 Tal y como se recoge en el Informe publicado por el Observatorio de la Sostenibilidad en España (2008) sobre la "Calidad del aire en las ciudades españolas, clave de sostenibilidad urbana".

3 El Séptimo Programa de Acción Comunitario en materia de Medio Ambiente aboga por una estrategia temática sobre la contaminación atmosférica con el objetivo de alcanzar niveles de calidad del aire que no dan lugar a riesgos inaceptables para la salud de las personas y el medio ambiente. 
actual, el turismo debe enfrentarse a nuevos retos cada vez más complejos, difusos y que generan mayor incertidumbre, como el cambio climático. Todo ello, unido a la intersectorialidad y las características propias de la actividad turística, hace inevitable la intervención pública, cuya eficiencia y pertinencia serán claves para determinar el éxito y la sostenibilidad futura de los destinos. Así pues, resulta imprescindible analizar y ampliar los instrumentos de acción pública que favorezcan la sostenibilidad futura del sector. ${ }^{4}$

\section{EL CONTROL DE LA CONTAMINACIÓN DEL AIRE ATMOSFÉRICO, COMO ANTESALA DE LAS ACTIVIDADES TURÍSTICAS}

Indudablemente, desde el comienzo de los tiempos, la naturaleza ha incidido e incide en el ser humano, si bien, éste ha modificado y transformado el medio físico en el que se asienta, llevando a cabo sus más que variadas y, cada vez más complejas, actividades económicas, lo que ha supuesto que la naturaleza haya tendido a adaptarse a las condiciones establecidas por el hombre; de este modo, esta coevolución, junto con la diversidad topográfica, geológica y orográfica, amén de con la variabilidad climática -estacional y temporal, con el paso de los años-, ha dado lugar a una amplia diversificación de la fauna y la flora, conformando así unos excepcionales ecosistemas mediterráneos, no exentos, ni mucho menos, de una notable vulnerabilidad frente a un complejo entramado de amenazas y riesgos vinculados, en los últimos tiempos, a la contaminación y degradación del aire. Y es que, la contaminación atmosférica suele ser mayor en las regiones donde predomina el clima mediterráneo continentalizado, a consecuencia de sus regímenes de precipitación, temperatura y aridez estacional, amén de la exposición continua al polvo sahariano que aumentan los niveles de partículas en suspensión, favoreciendo su deposición en la flora y, por ende, entrando en la cadena trófica, así como modificando la composición química de la atmósfera, lo que repercute en los ciclos biológicos y bioquímicos de los sistemas acuáticos y terrestres.

Con el fin de establecer un régimen de control de los niveles de emisión, la Comunidad de Madrid articula su territorio con una Red de Control y Vigilancia de la Calidad del Aire $^{5}$ ), cuya finalidad ${ }^{6}$ es la de registrar los niveles de concentración de los principales

4 Santos-Lacueva, R., Anton Clavé, S y Saladié, O (2017). "Discontinuidades y limitaciones de los últimos planes turísticos de España en relación a la sostenibilidad ambiental del turismo de sol y playa”., Cuadernos de Turismo, n 40, pp. 599-626 Universidad de Murcia ISSN: 1139-7861 eISSN: 1989-4635 DOI: http://dx.doi. org/10.6018/turismo.40.310121

5 En el año 2010 obtuvo el Certificado de Calidad según ISO9001:2008

6 Comunidad de Madrid (2017): La finalidad principal de la Red de Calidad del Aire de la Comunidad de Madrid es registrar los niveles de concentración de los principales contaminantes atmosféricos, de forma que se puedan definir los niveles de calidad del aire y recomendar, en su caso, actuaciones y políticas acordes con las situaciones de contaminación planteadas.

Los objetivos más relevantes perseguidos por la Red de Calidad del Aire son:

- Informar a los ciudadanos del estado de la calidad del aire.

- Localizar las zonas de la Comunidad de Madrid con mayores problemas de contaminación.

- Conocer la evolución de la contaminación atmosférica en el conjunto del territorio de la Comunidad y a lo largo del tiempo.

Cumplir con las Directivas europeas en materia de protección del aire atmosférico que exigen conocer la contaminación allí donde se produzca; estas series de datos históricos permiten evaluar la calidad del aire y definir la política ambiental más acorde con la realidad territorial. 
contaminantes atmosféricos que permitan implementar en el territorio, medidas de control y mitigación de emisiones, lo que favorece o puede favorecer la reducción o eliminación -hoy por hoy, utópica-, de los riegos causados por la sobreexposición a dichas sustancias contaminantes, tanto para el ser humano como para el medioambiente.

Tal y como podemos observar en el mapa adjunto (Figura 1a), la red de calidad se encuentra conformado por veintitrés estaciones automáticas fijas -amén de por un conjunto de estaciones móviles, y, sin contar con el municipio de Madrid que tiene su propio entramado de estaciones-, organizadas en siete zonas de estudio, y clasificadas por tipologías -fondo urbano, urbanas industriales, urbanas de tráfico, ámbito rural y ámbito rural orientado a la protección de la vegetación ${ }^{7}$-, encargadas de la recogida de datos de las emisiones de dióxido de azufre, dióxido de nitrógeno, óxidos de nitrógeno, partículas en suspensión, monóxido de carbono, ozono, benceno y metales pesados; aunque, podemos comprobar que no existen estaciones de medición fija en el conjunto del territorio de la Comunidad de Madrid, de hecho, de las existentes tienden a concentrarse entorno al Corredor del Henares y el sur de Madrid, lo que resta calidad a la información obtenida que, en muchos casos, tiende a generalizarse en el conjunto del territorio de la Comunidad, a través de la zonificación señalada, y a la que denominan áreas homogéneas. Además, no todas las estaciones toman muestras del conjunto de gases emitidos -cada zona tiene estaciones que miden emisiones de gases concretos, consecuencia directa de la zonificación estipulada. Como podemos ver en la Figura 1b, las estaciones de medición se localizan, principalmente (entorno al 65\%) entre los 50.000 y los 200.000 habitantes, y cuya área de influencia presente los mismos niveles de población, así como en municipios con menos de 10.000habitantes (aproximadamente, un 26\%); si bien, en municipios con poblaciones entre los 10.000 y los 50.000habitantes tan solo encontramos dos estaciones fijas.

Si bien, a pesar de ello, la Red muestran claramente que las principales causas de contaminación atmosférica en la Comunidad de Madrid procede de fuentes de emisión industrial, los usos doméstico, las actividades comerciales y el tráfico rodado, por lo que los distintos contaminantes presentan una amplia variabilidad en el territorio, dependiendo de si nos encontramos en un área urbana, rural o rururbana; de la tipología de usos del suelo; o de las condiciones climáticas regionales que delimitan la estacionalidad y temporalidad de las emisiones, así como las cantidades y tipos de contaminantes. Con ello, podemos señalar que la contaminación de Madrid está marcada por la variabilidad espacial, la variabilidad temporal -consecuencia directa de las condiciones climáticas, la estacionalidad y las diferencias existentes entre el día y la noche- y, por los episodios críticos que marcan condiciones de riesgo extremo para la salud humana-concretamente en situaciones anticiclónicas permanentes o persistentes.

Obtener la información necesaria para poder definir los planes de actuación marcados por las Directivas europeas en caso de superación de umbrales de alerta; estas Directivas definen los niveles de contaminación permitidos y los posibles planes de actuación a poner en marcha en caso de superación de dichos niveles.

7 Si bien, tras el análisis de datos recogidos en los "Estadísticos 2016 del Ministerio" de la Dirección General de Medio Ambiente de la Comunidad de Madrid (2017), se observa que la mayor parte de las estaciones tienen carácter residencial, con independencia de que correspondan a las tres zonas de aglomeración o a las tres zonas rurales. 


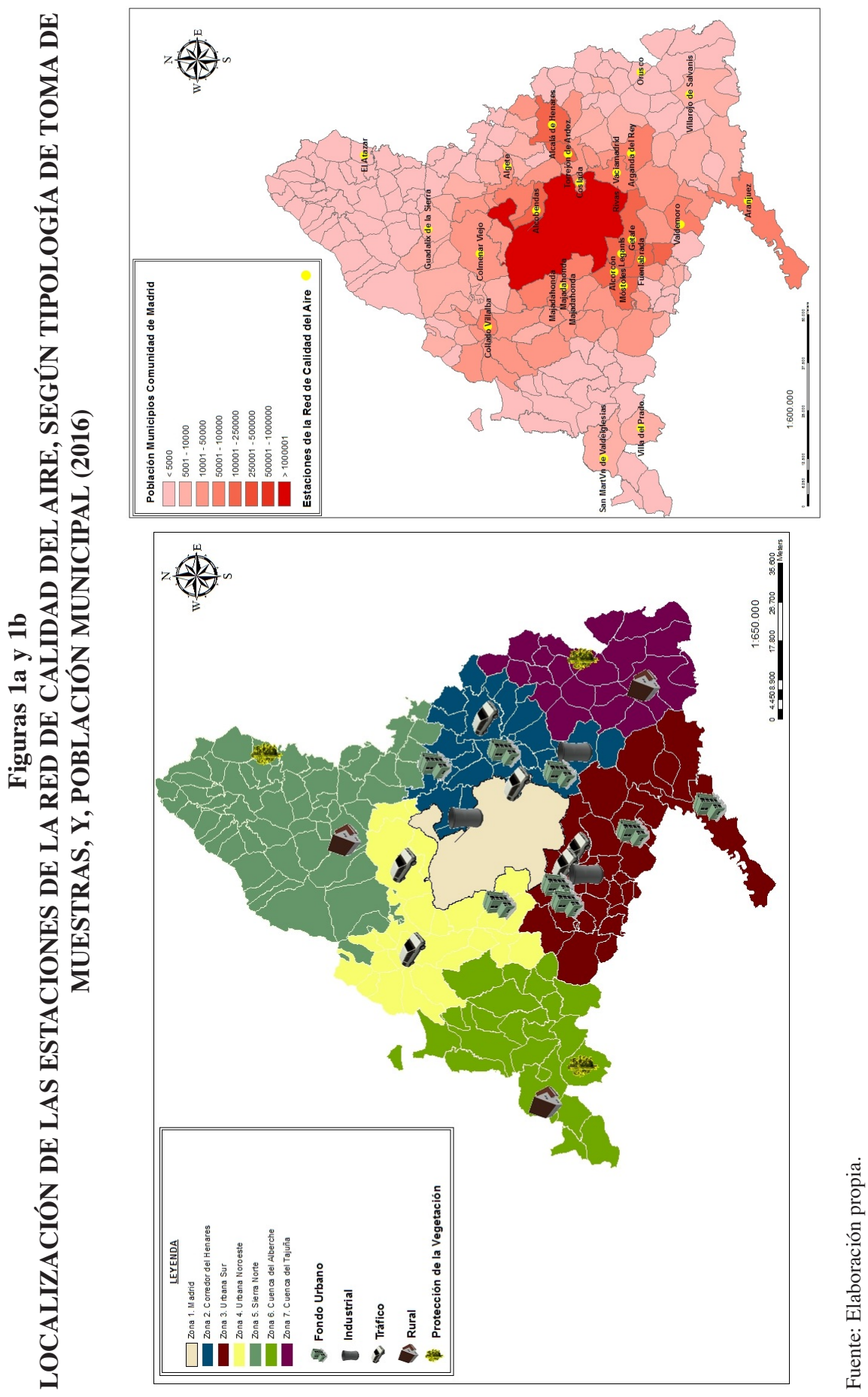


Además, cobra notable importancia señalar que las estaciones de la Red de Vigilancia se encuentran situadas en espacios concretos que, en cierto modo, pueden incidir en los resultados obtenidos. A tenor de lo recogido en el mapa siguiente (ver Figura 2), las estaciones de medición se localizan principalmente en áreas urbanas o próximas a urbes, de carácter residencial y, en su mayoría, en entornos considerados como espacios naturales protegidos -con independencia del régimen de protección que ostenten-, lo que nos da cuenta de la incidencia de las variaciones en los niveles de emisión, además de la repercusión que pueden tener en el medio físico, en general, y, en la población en particular. Indiscutiblemente, la Comunidad de Madrid posee notables ecosistemas, conformados por una biodiversidad única y que brindan al conjunto de la población de unos valores y servicios ambientales que, en los momentos actuales, se encuentran en continuo riesgo, a consecuencia directa de la contaminación atmosférica. Los espacios naturales de la Comunidad se encuentran en peligro constante y ven incrementado sus niveles de vulnerabilidad a consecuencia del continuo aumento de los niveles de $\mathrm{O}_{3}$ producto de las elevadas temperaturas del aire y la radiación solar; igualmente, la estabilidad de las masas de aire y el incremento de deposiciones de nitrógeno, repercuten de manera directa en el medio natural. En dichos territorios, tan solo cuentan con la acción de los factores bióticos y abióticos que transforman esa realidad y, en muchos caso, parece que la presión de las actividades humanas en el medio ambiente no son tan dañinas ni generan ningún tipo de riesgo, pero no se tiene en cuenta que, la capacidad de carga de contaminantes en estos espacios no es infinita.

Y, es que, el control de la contaminación del aire atmosférico debe tener en cuenta otros factores como la climatología, la topografía, las medidas de protección ambiental, la afección a la población o la participación del conjunto de los municipios en su análisis, medición y evaluación de la calidad del aire; de hecho, cobre gran importancia la incorporación en los Planes de Ordenación Urbana la preservación y conservación del aire atmosférico, amén de tener en cuenta que los procesos de emisión de sustancias contaminadoras y degradantes de la atmósfera puede afectar a más de un territorio, a consecuencia del transporte y la dispersión de éstas movidas por el viento, lo que conllevaría el trabajo conjunto de las distintas Administraciones ${ }^{8}$. Por lo que, junto con un eficiente control, la gestión de la contaminación del aire atmosférico debe conllevar un análisis multidisciplinar y multidisciplinario -por parte, no solo de las instituciones y entidades públicas, sino de las entidades privas y la población en general, para evitar así emplear malas práxis que conllevan una reducción de la calidad de vida y en unas condiciones ineficientes. Todo ello sin olvidar, como señalamos anteriormente, que los procesos de contaminación del aire no solo son consecuencia de la emisión directa de sustancias en un área determinada, sino que se transportan de un lugar a otro, de manera difusa, sin control y sin medición, con lo que homogeneizar territorios

8 Indiscutiblemente, la contaminación atmosférica no respeta fronteras ni distancias, por lo que los riesgos provocados por un proceso de emisión de sustancias no solo afecta a la población que vive o reside en un determinado territorio en el que se encuentra el foco de contaminación. Esta es otra de las cuestiones que deberían tenerse en cuenta a la hora de gestionar las amenazas, los peligros, los daños y los riesgos originadas por la emisión, distribución, concentración o dispersión en un determinado territorio, amén del clásico dilema económico y sus correspondientes soluciones propustas por Coase o Pigou. 


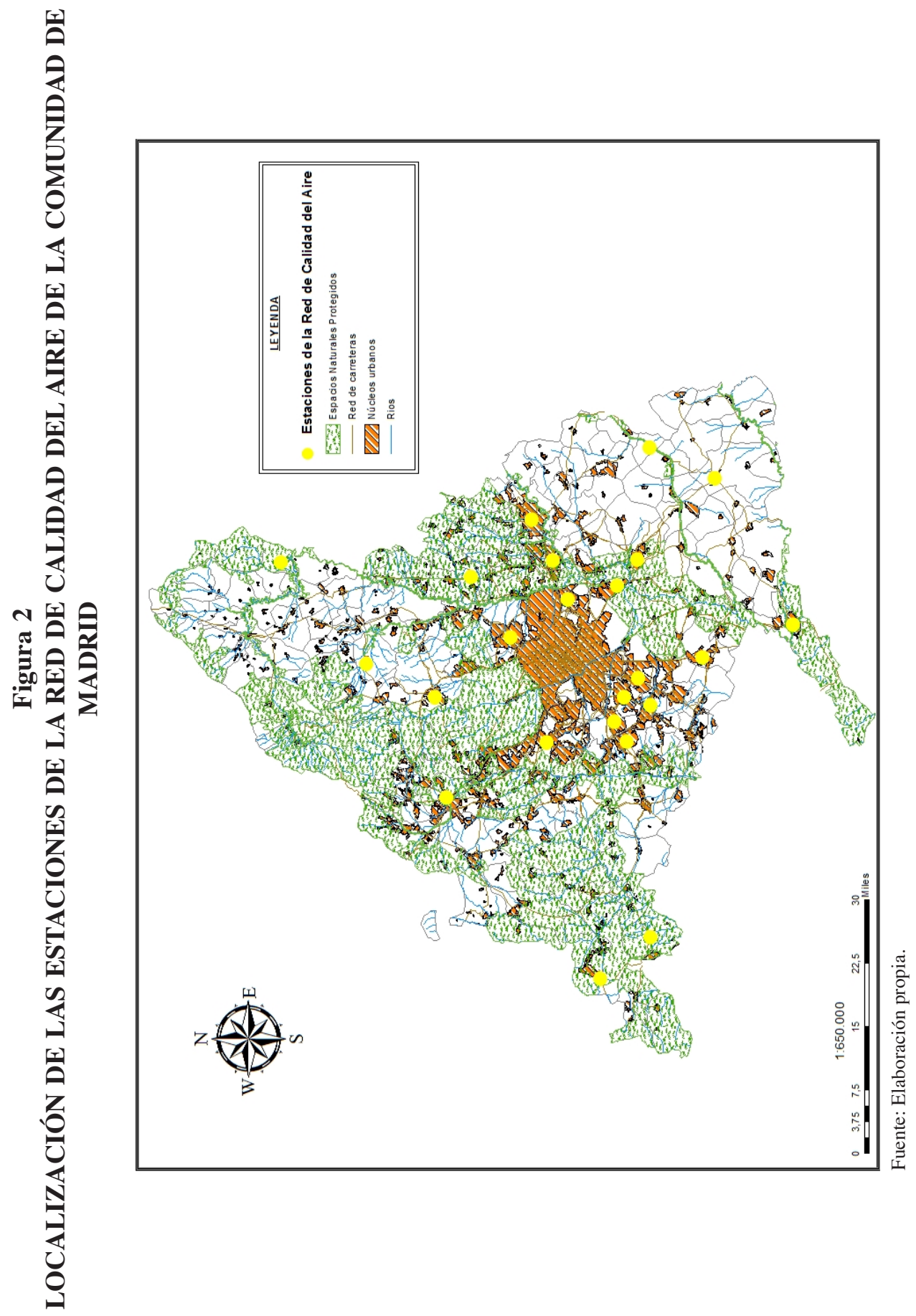




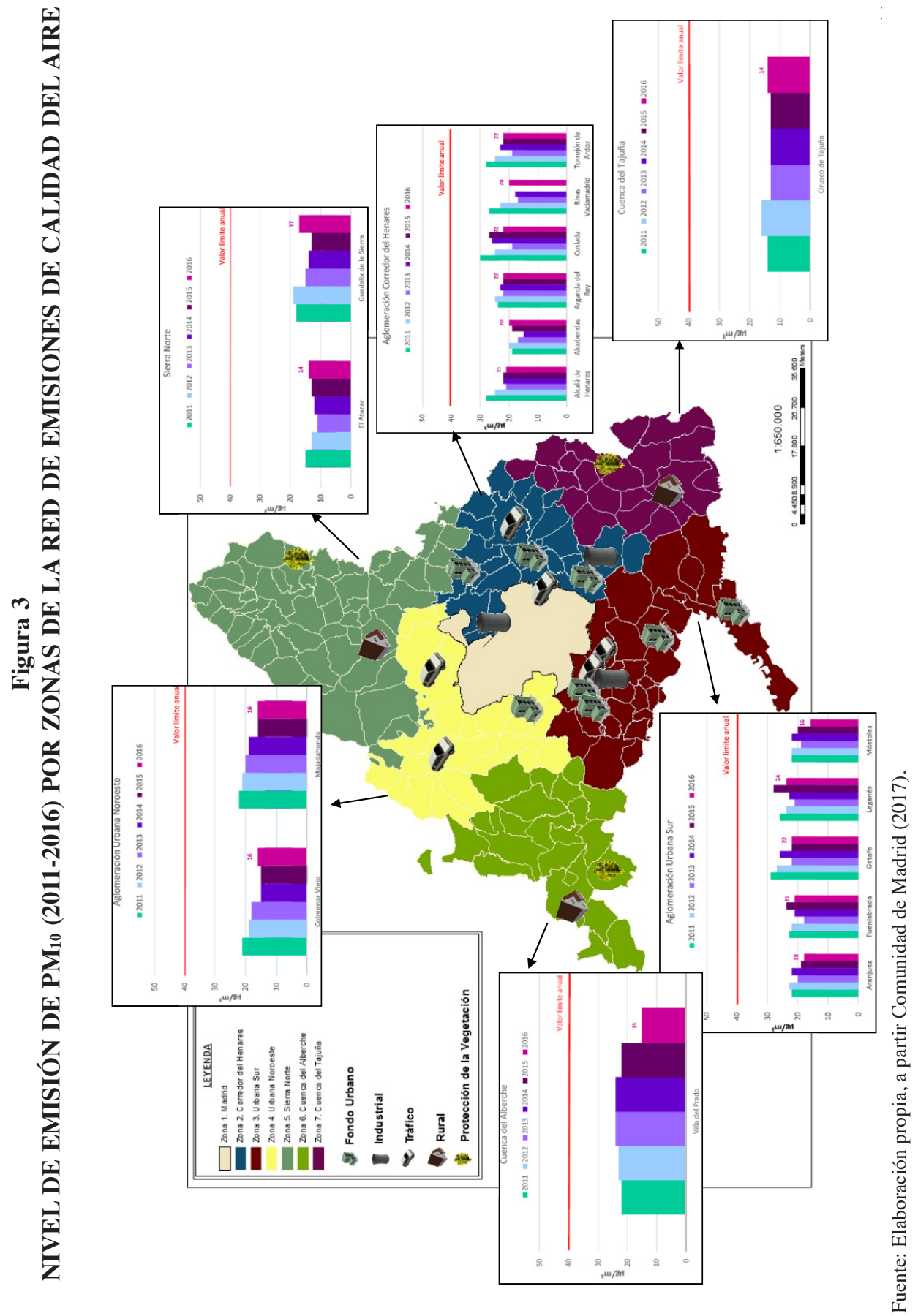




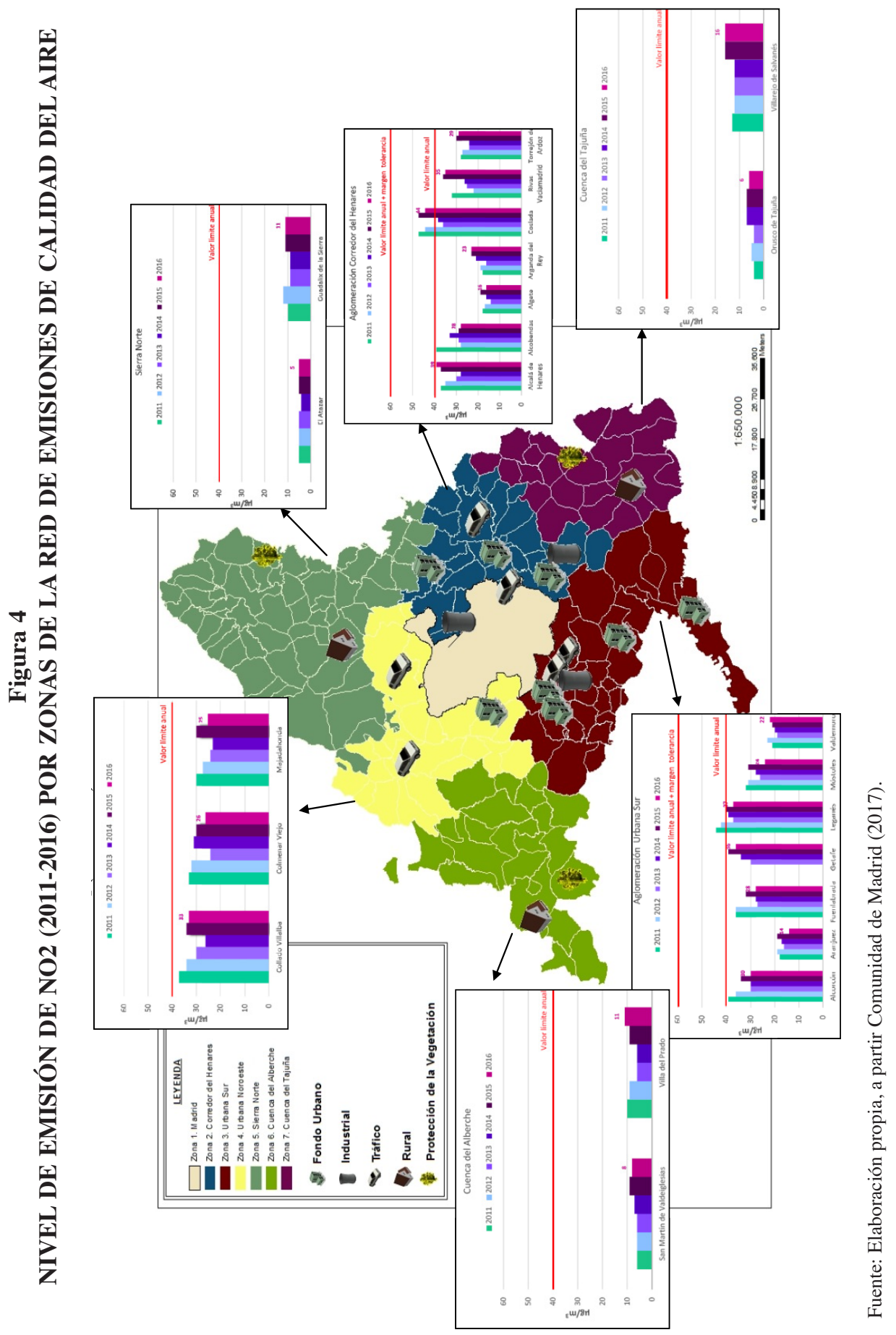

Cuadernos de Turismo, 44, (2019), 381-411 
y particularizar en fuentes de emisión concreta, no da a conocer la realidad compleja del proceso de contaminación en un determinado espacio -en este caso, municipio 9 .

Así pues, la Comunidad de Madrid se ve afectada, principalmente, como en el conjunto de la Cuenca Mediterránea por las emisiones de partículas, nitrógeno (N) y ozono troposférico $\left(\mathrm{O}_{3}\right)^{10}$, como podemos observar en las Figuras 3, 4, 5 y 6. En las cuales, se nos muestra como los niveles de emisiones gases contaminantes han sufrido un ligero descenso en el conjunto de la Comunidad de Madrid, a lo largo del año 2016 respecto al año 2011 (a excepción del ozono troposférico y los HTC que se mantienen al mismo nivel), si bien, esto no ha supuesto un cambio continuo a lo largo del tiempo -claro ejemplo lo encontramos en el año 2015, donde se incrementaron los niveles de emisión-, y, aunque en la mayor parte de los casos se encuentran por debajo de los valores límite y niveles críticos estipuladas por la legislación, continúan generando importantes impactos en el aire que respiramos.

Además, a pesar de que se redujesen drásticamente dichas emisiones, no quiere decir que se eliminasen los riesgos asociados a la contaminación, pues sus efectos estarían latentes tanto en el medio como en la población expuesta. Así pues, podemos apreciar que los niveles de emisión de sustancias nocivas son muy elevadas, especialmente de Ozono troposférico $\left(\mathrm{O}_{3}\right)$, Óxido de Nitrógeno (NO), Partículas en suspensión, Dióxido de Nitrógeno $\left(\mathrm{NO}_{2}\right)$ y Dióxido de Azufre $\left(\mathrm{SO}_{2}\right)$.

\section{Figura 5 \\ EVOLUCIÓN DE LOS NIVELES DE EMISIÓN EN LA COMUNIDAD DE MADRID (2011-2016)}

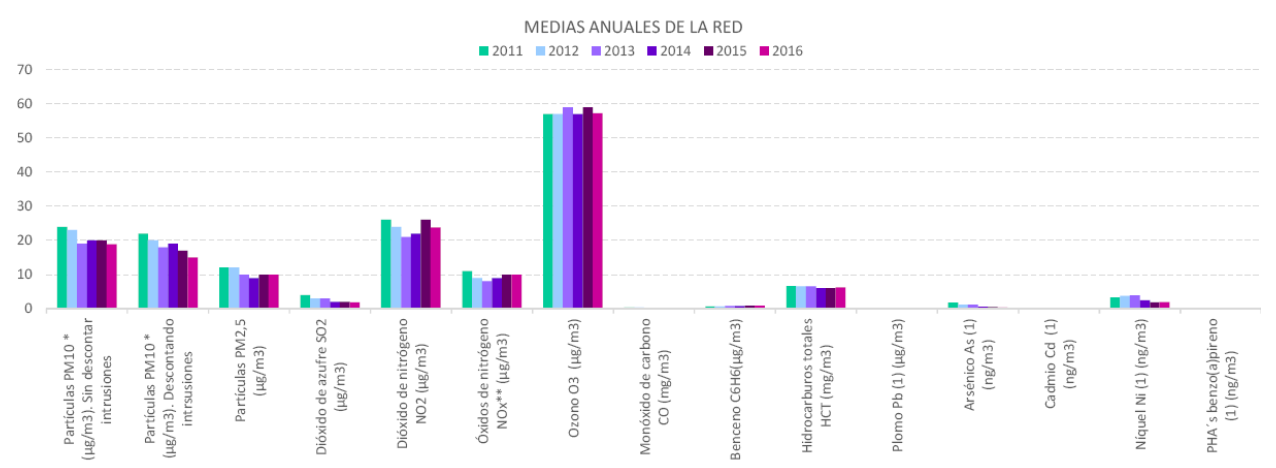

Fuente: Informe de la Calidad del Aire de la Comunidad de Madrid (2017).

9 Y es que, la estimación de las cargas de deposición de contaminantes sigue presentando importantes incertidumbres y desafíos, tanto en términos de modelado como de mediciones (Simpson et al., 2014), especialmente en estudios a pequeña escala regional y en regiones con topografía compleja o bajo la influencia de fuentes locales de emisión (García-Gómez et al., 2014).

10 Siguiendo los trabajo de García Gómez, H. et alii (2014) y Ochoa-Hueso, R. et alii (2017). 
Si analizamos lo mapas y el gráfico adjuntos (ver Figuras 3, 4, 5 y 6), se pone de manifiesto que, aunque aparentan ser territorios homogéneos, no presentan los mismos niveles de emisión para cada una de las sustancias seleccionadas, ni siguen una línea temporal igual. En el caso concreto de las Zonas denominadas "Sierra Norte", "Cuenca del Tajuña" y "Cuenca del Alberche", encontramos "bajos" niveles de emisión de dióxido de nitrógeno $\mathrm{y}$, en cierto modo de particulas $\mathrm{PM}_{10}$-en comparación con el resto de las zonas-, mientras que llama la atención los elevadas cantidades de ozono troposférico $\left(\mathrm{O}_{3}\right)$ que se disparan con respecto al resto de zonas de la Red. Un reciente estudio ha puesto de manifiesto que los ecosistemas de las áreas de montaña en España, donde las estaciones de monitoreo son aún más escasas, están frecuentemente expuestos a excedencias de cargas de moonóxido de nitrógeno (García Gómez et al., 2017), lo que supone una dispersión ${ }^{11}$ y precipitación en el suelo de dichas sustancias (NO) que reducen el pH del suelo, afectando a los microorganismos (principalmente, microbacteriana) y en la actividad enziemática global, encargada de la descomposición de la hojarasca (todo ello teniendo en cuenta que los riesgos varian dependiendo de si nos encontramos ante árboles perennes o caducifolios, puesto que el intercambio de gases y la capacidad antioxidante de los árboles de hoja caduca se ven más afectados por las elevadas concentraciones de sustancias contaminantes, en genral, y de ozono, en particular), aunque poco se ha estudiado, sobre la presión que ejerce sobre la fauna endémica. Además, en las zonas montañosas de la cuenca mediterránea también registran con frecuencia concentraciones muy elevadas de $\mathrm{O}_{3}$ que no son recogidas en las redes de vigilancia de la calidad del aire (Díaz de Quijano et al., 2009) que, en su unión con el monóxido de nitrógeno, puede llega a alterar las emisión de Compuestos Orgánicos Volátiles y afectar la interacción entre biosfera y atmósfera. A su vez, la disponibilidad de nitrógeno puede compensar parcialmente los efectos del ozono troposférico sobre la biomasa -cando estos son moderados-, pero la exposición continua al ozono reduce los efectos de fertilización a mayor cantidad de monóxido de nitrógeno.

Por su parte, en el conjunto de zonas denominadas de "aglomeración", donde las emisiones son catalogadas de "industriales", "tráfico" y "fondo urbano", los procesos de contaminación son diferentes y, por ende, también se ven modificados los patrones de "riesgo". Así pues, los niveles de ozono troposférico son inferiores en zonas de aglomeración que en áreas rurales, mientras que las emisiones de dióxido de nitrógeno son ligeramente superiores y las partículas en suspensión $\mathrm{PM}_{10}$ están, prácticamente, al mismo nivel en ámbas zonas.

11 La dispersión puede reducir la concentración de un contaminante a la que se ve expuesto un determinado receptor, aunque no reduce la cantidad total de material procedente de Un emisario. Cuando el contaminante se reduce a una simple molestia, como un olor desagradable, la dispersión puede resultar un método adecuado. Pero si el material es de tipo permanente o acumulativo, como los metales pesados, la dilución no resolverá el problema de la contaminación atmosférica. La dispersión es compleja y muy dañina, puede incrementar sustancialmente los niveles de "riesgo" teniendo en cuenta las condiciones meteorológicas locales y superficiales del suelo. Así, por ejemplo, en los climas fríos, especialmente cuando se producen precipitaciones de nieve, se producen con frecuencia inversiones térmicas que atrapan a los contaminantes cerca del suelo y dan lugar a exposiciones especialmente altas. De forma análoga, si los emisarios contaminantes están situada en un valle, los penachos pueden ascender y descender por el valle o quedar bloqueados por las montañas cercanas, sin expandirse ni dispersarse como sería deseable (Elias, J., (1998). "Control de la contaminación atmosférica", en AA.VV. (1998) "Enciclopedia de salud y seguridad en el trabajo". Oficina Internacional del Trabajo. ISBN : 84-8417-047-0 


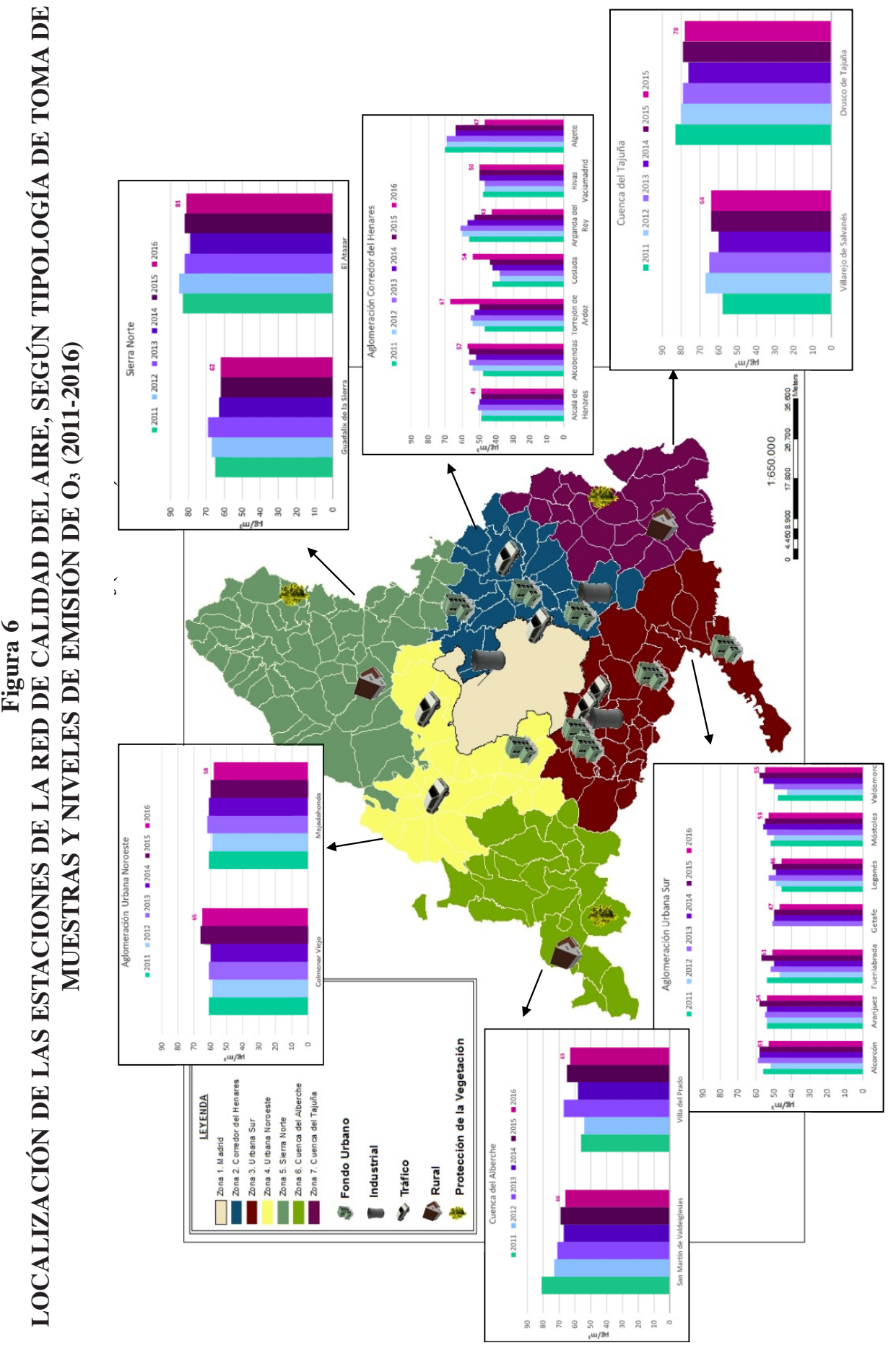

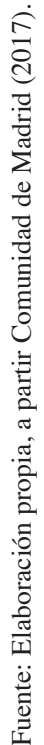


A su vez, los elevados niveles de emisión de sustancias $\mathrm{NO}_{2}$, provoncan reacciones que incrementan la formación de sulfato amónico y nitrato de amonio que incrementan los niveles de $\mathrm{PM}_{10}$ y $\mathrm{PM}_{2,5}$, y eso podría favorecer que los niveles de $\mathrm{PM}_{10}$ sean tan elevados en las zonas de "aglomeración", principalmente. Mientras que las emisiones de Ozono troposfércio afectan a la elevación de las temperaturas en los territorios en los que sus niveles son más elevados lo que provoca alteraciones en la flora, afectando a la coloración y necrosis de sus hojas, cambios en el crecimiento de la planta y una constante y paulatina reducción de su productividad, lo que repercute más que notablemtene a las áreas de viñedo y olivares, así como a los pinares y hayedos de la Comunidad de Madrid.

\section{RIESGOS INHERENTES A LA CONTAMINACIÓN ATMOSFÉRICA, CON REPERCUSIÓN EN EL TURISMO}

Lo anteriormente expuesto, puede generar numerosos riesgos ambientales que afectan al medio físico y a la población, así como a las actividades turísticas, puesto que estos territorios que se encuentran diariamente expuestos a emisiones de partículas en suspensión se ven afectados por la alteración de los niveles de precipitación, por la acidificación de sus suelos, por cambios en las condiciones climáticas y, más concertación sobre los balances radiactivos, amén de servir de sustrato para la fijación de otras sustancias contaminantes o intensificar la oxidación del dióxido de azufre convirtiéndolo en ácido sulfúrico, etc., lo que produce toxicidad en las plantas y cambios en la realización de la fotosíntesis -sean destinadas al consumo directo o no, como en el caso de las zonas de bosque-, además reducen la calidad y esperanza de vida de la población residente en estos entornos, y afectan negativamente a su salud.

Y, es que, teniendo en cuenta los datos recogidos en las Figuras 7, 8 y $9{ }^{12}$ observamos que, a día de hoy, siguen existiendo municipios en los que se superan los niveles límite de emisión, como es el caso concreto de Coslada -otros municipios como Alcalá de Henares, Leganés, Getafe o Rivas Vaciamadrid superan los $35 \mu \mathrm{g} / \mathrm{m}^{3}$-. Indiscutiblemente, su localización geográfica y la disposición vs. crecimiento de sus actividades económicas, propician esta situación, haciendo al territorio especialmente vulnerable ante el riesgo de respirar gases sumamente contaminantes como son los óxidos de nitrógenos, especialmente el dióxido de nitrógeno, puesto que potencia las reacciones químicas producidas por los óxidos de nitrógeno que generan ácido nítrico (altamente corrosivo y que incrementa los riesgos de producir quemaduras), potencian la formación de $\mathrm{PM}_{10}$ y $\mathrm{PM}_{2,5}$, amén de tener una gran repercusión en la salud humana puesto que ocasiona dificultades respiratorios, infección de las vías respiratorias, afecciones en órganos vitales como el hígado o el bazo, produce problemas en el sistema inmunitario, circulatorio y pulmonar.

12 Señalando que, en la representación gráfica recogida en el trabajo, se tienen en cuenta los valores límite establecidos por la Unión Europea, que son superiores a la marcada y recomendada por la Organización Mundial de la Salud, que se muestra contraria a la legislación vigente. 
Por otra parte, del conjunto de estaciones que analizan y recogen valores de emisión de dióxido de azufre, encontramos los municipios de carácter rural como El Atazar, Villa del Prado y Orusco de Tajuña lo que, a pesar de no superarse los niveles de emisiones permitidas -lo que no quiere decir que no genere riesgos y daños-, repercute en un medio natural importante, afectando a una vegetación y a las actividades económicas del sector primario. Y es que, el dióxido de azufre $\left(\mathrm{SO}_{2}\right)$ afecta directamente a la vegetación puesto que es absorvida, a través de las hojas y el tallo, en cantidades variables, dependiendo e las concentraciones existentes en el aire. Por ello, según la la cantidad de dióxido de azufre aborvida por unidad de tiempo, varian los efectos bioquímicos y fisiológicos que tienen lugar en el tejido vegetal, destacando, principalmente, la degradación de la clorofila, variación en los procesos de desarrollo de la fotosíntesis, aumento de la frecuencia respiratoria y cambios en el metabolismo de las proteínas -amén de que los líquenes o el musgo son mucho más sensibles a las alteraciones del aire por $\mathrm{SO}_{2}-$. Por lo que, según la duración de la exposición y la frecuencia y secuencia de impacto, se producen diversos daños que se incrementan, a mayor exposición y cantidad, provocando nuevos riesgos, vinculados a la modificación del clima o la salud humana. Siguiendo la misma dinámica que con las emisiones de $\mathrm{SO}_{2}$, encontramos las estaciones que recogen datos correspondientes a monóxido de carbono, y, amén de sorprender los valores relativamente bajos, destaca el escaso número de estaciones encargadas de contabilizar el $\mathrm{CO}$ en el aire atmosférico en la Comunidad. Esto es algo recurrente en cuanto a sustancias como en las partículas en suspensión o en el Benceno, lo que genera una enorme falta de información general en el conjunto de la Comunidad de Madrid, impidiendo a la población y a las administraciones tener en cuenta las amenazas a las que debe enfrentarse la población en una situación, claramente, en riesgo continuo. 
Figura 7

NIVEL DE EMISIONES POR SUSTANCIAS Y VALORES LÍMITE EN LA COMUNIDAD DE MADRID (2016)
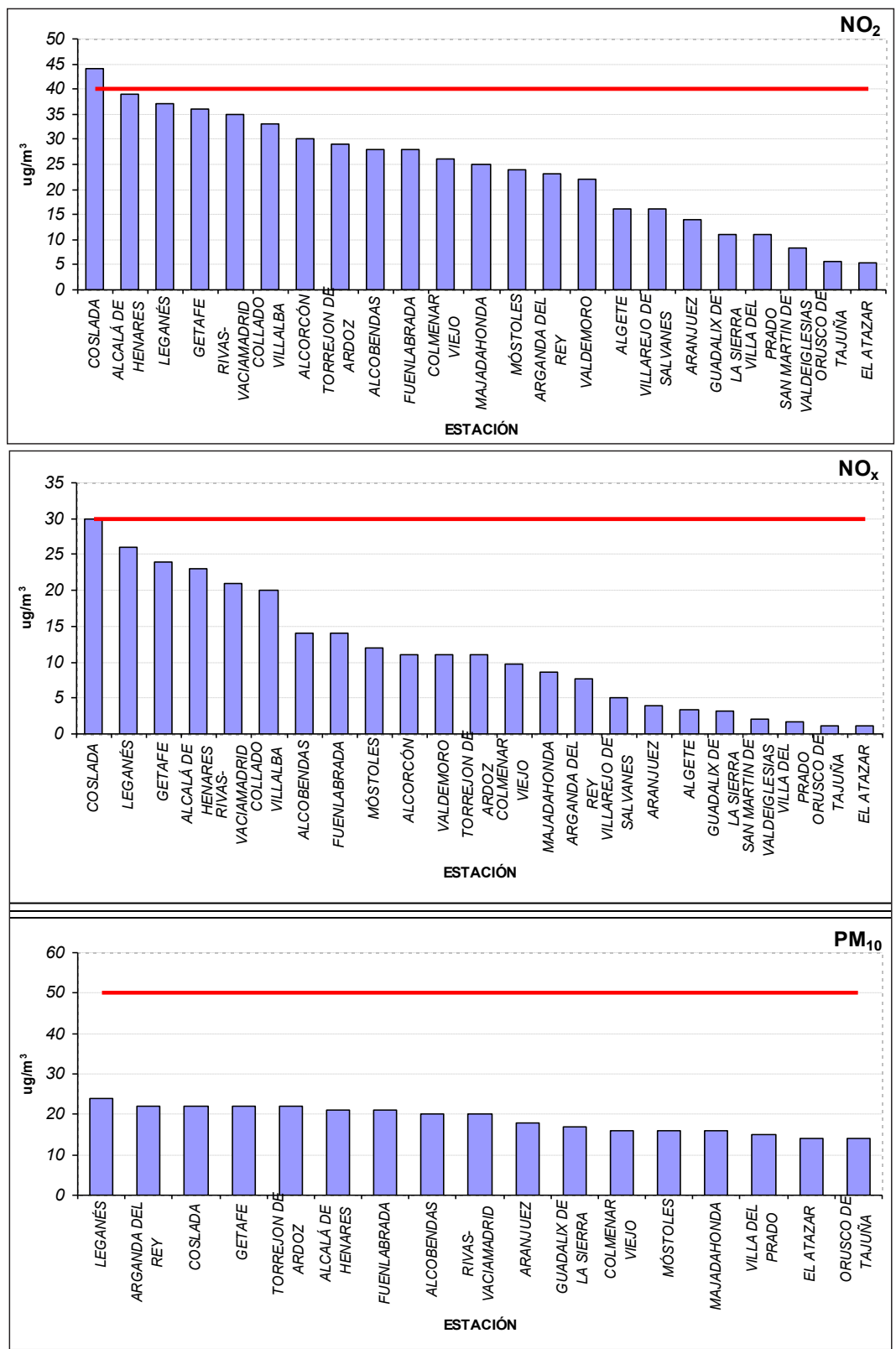

Fuente: Elaboración propia, a partir de Comunidad de Madrid (2017). 
Figura 8

NIVEL DE EMISIONES POR SUSTANCIAS Y VALORES LÍMITE EN LA COMUNIDAD DE MADRID (2016)
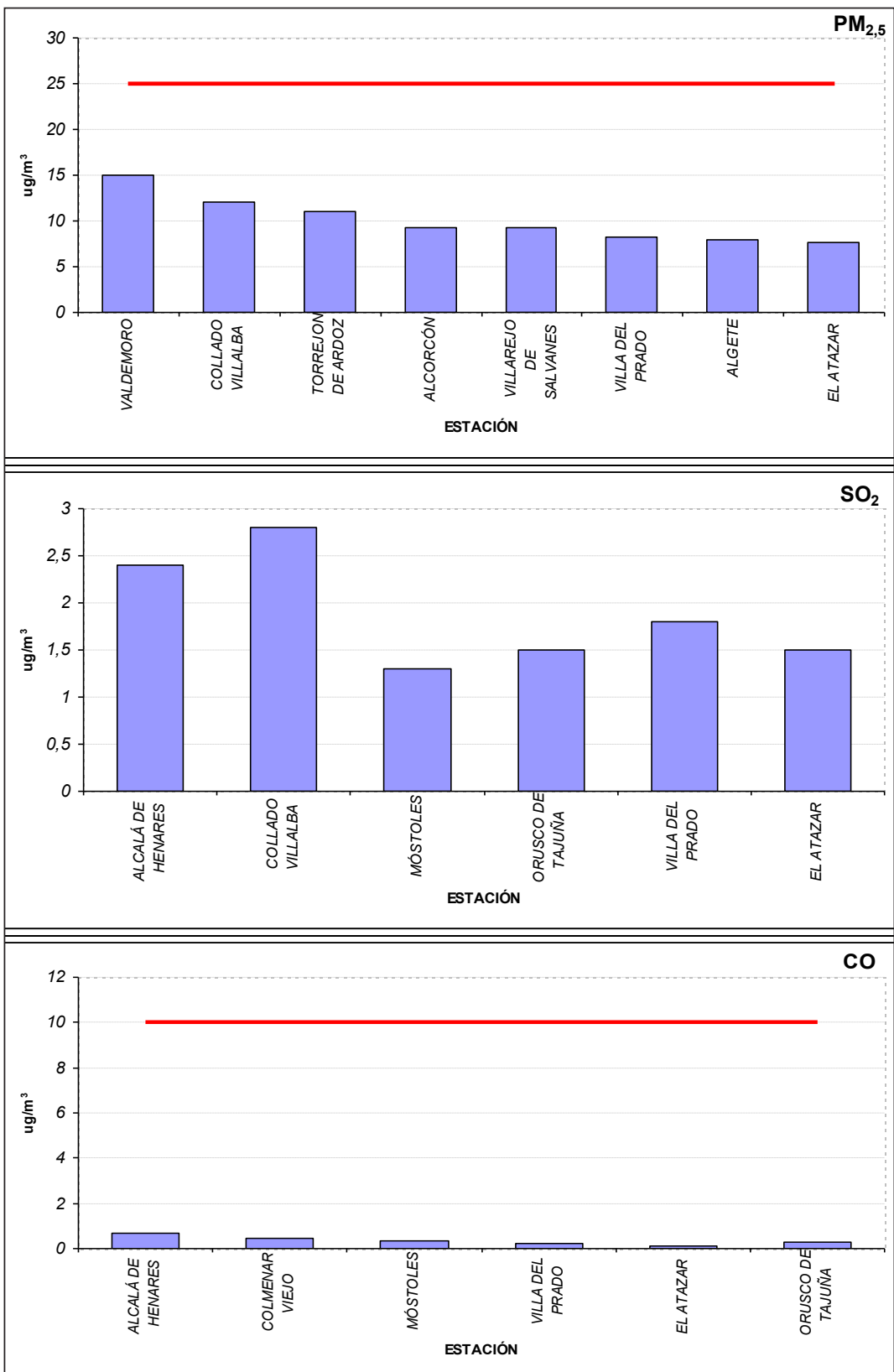

Fuente: Elaboración propia, a partir de Comunidad de Madrid (2017). 
Igualmente, no debemos olvidar que las condiciones económicas, socioculturales y políticas son esenciales para prevenir y mitigar los niveles de riesgo y, para dar respuestas eficientes por parte de las Administraciones, con el fin de evitar las situaciones que se recogen en el presente estudio. Y, es que, lejos de lo que podemos pensar, estas condiciones de continuo proceso de contaminación y degradación conllevan no solo riesgos en el medio físico o en la propia población, sino que generan nuevos riesgos económicos, sociales, políticos y culturales. En cuanto a la dimensión económica del riesgo por contaminación atmosférica debemos resaltar las pérdidas monetarias que potencialmente se ocasionan en regiones, territorios o situaciones de riesgo que conllevan o se sirven de análisis coste eficiencia y coste eficacia para poder solventar los problemas emanados.

Por su parte, la dimensión social y cultural se ven afectadas por los procesos de contaminación del aire atmosférico a través de la degradación de las relaciones sociales, los procesos de identidad social, los valores compartidos, el pensar en el resto de población que vive y convive en un determinado espacio, todo eso se ve amenazado y vulnerado por el uso continuo y constante de sustancias contaminantes que no solo van a perjudicar al que los usa sino al resto de la sociedad; además, la presencia de un riesgo antrópico como el que estamos analizando puede ser percibido como una amenaza a las relaciones sociales de una población y, aunque no existiera un daño real para la salud, no todo el mundo gestiona el riesgo de la misma madera. Por ello, cobra notable importancia los factores políticos e institucionales, pues sirven de nexo de unión entre las instituciones y la población, marcando así las relaciones de confianza, justicia, equidad, conflicto,..., orientado a la gestión del riesgo, puesto que las Instituciones -con independencia de la escala en la que se encuentren- son las encargadas de la gestión, control y regulación de situaciones de riesgo como es la que nos atañe.

Por ello, promover políticas e inversiones que respalden un transporte más limpio, viviendas de eficiencia energética, la generación de energía, la industria y una mejor gestión de los residuos municipales reducirían las fuentes clave de contaminación urbana del aire atmosférico. Además, la reducción de las emisiones al aire de sustancias emitidas por fuentes energéticas como el carbón o la biomasa, la incineración de residuos agrícolas, los incendios forestales y ciertas actividades agroforestales favorecerían el descenso de los niveles de contaminación atmosférica en áreas rurales y rururbanas.

Por otro lado, debemos señalar que, a lo largo del año 2016, se han producido numerosas situaciones de riesgo extremo, a la hora de superarse los niveles máximo permitidos por la Ley, concretamente en emisiones de Ozono troposférico $\left(\mathrm{O}_{3}\right)$ y partículas en suspensión, existiendo una clara diferenciación espacial entre ambas pues el ozono se dispara en zonas denominadas "rurales" mientras que las partículas son más elevadas en zonas de "aglomeración". 


\section{Figura 9 \\ NIVEL DE EMISIONES POR SUSTANCIAS Y VALORES LÍMITE EN LA COMUNIDAD DE MADRID (2016)}
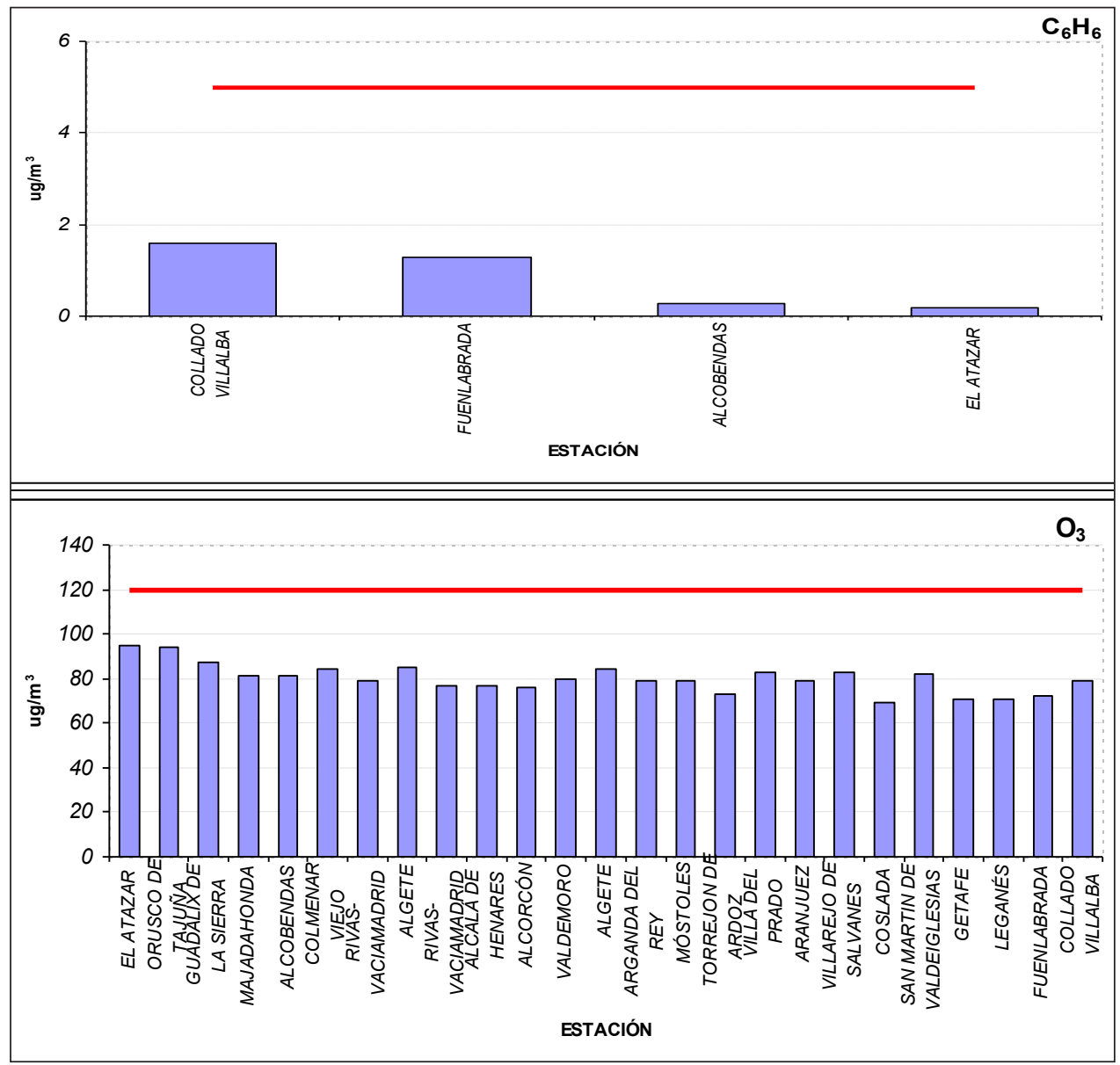

Fuente: Elaboración propia, a partir de Comunidad de Madrid (2017).

Como podemos observar en la Figura 10, los niveles de ozono troposférico llegarona superarse en más de 60 días en la estación de El Atazar y Orusco de Tajuña o casi en 50 días en Rivas Vaciamadrid, mientras que en las zonas de aglomeración de Leganés o Torrejón de Ardoz se han visto expuestos a superaciones de emisiones de partículas $\mathrm{PM}_{10}$ en veinte ocasiones. Indiscutiblemente, todo esto nos permite marcar líneas divisorias en el territorio, en cuanto a los procesos de emisión y superación de niveles de contaminación. Además, debemos tener presente que, aunque no se superen los límites establecidos, no quiere decir que no exista el riesgo real y latente de la contaminación atmosférica en la Comunidad de Madrid, sino, simplemente, que no se condena su emisión. 
Figura 10

DÍAS EN LOS QUE SE SUPERARON LOS VALORES LÍMITE EN LA COMUNIDAD DE MADRID (2016)
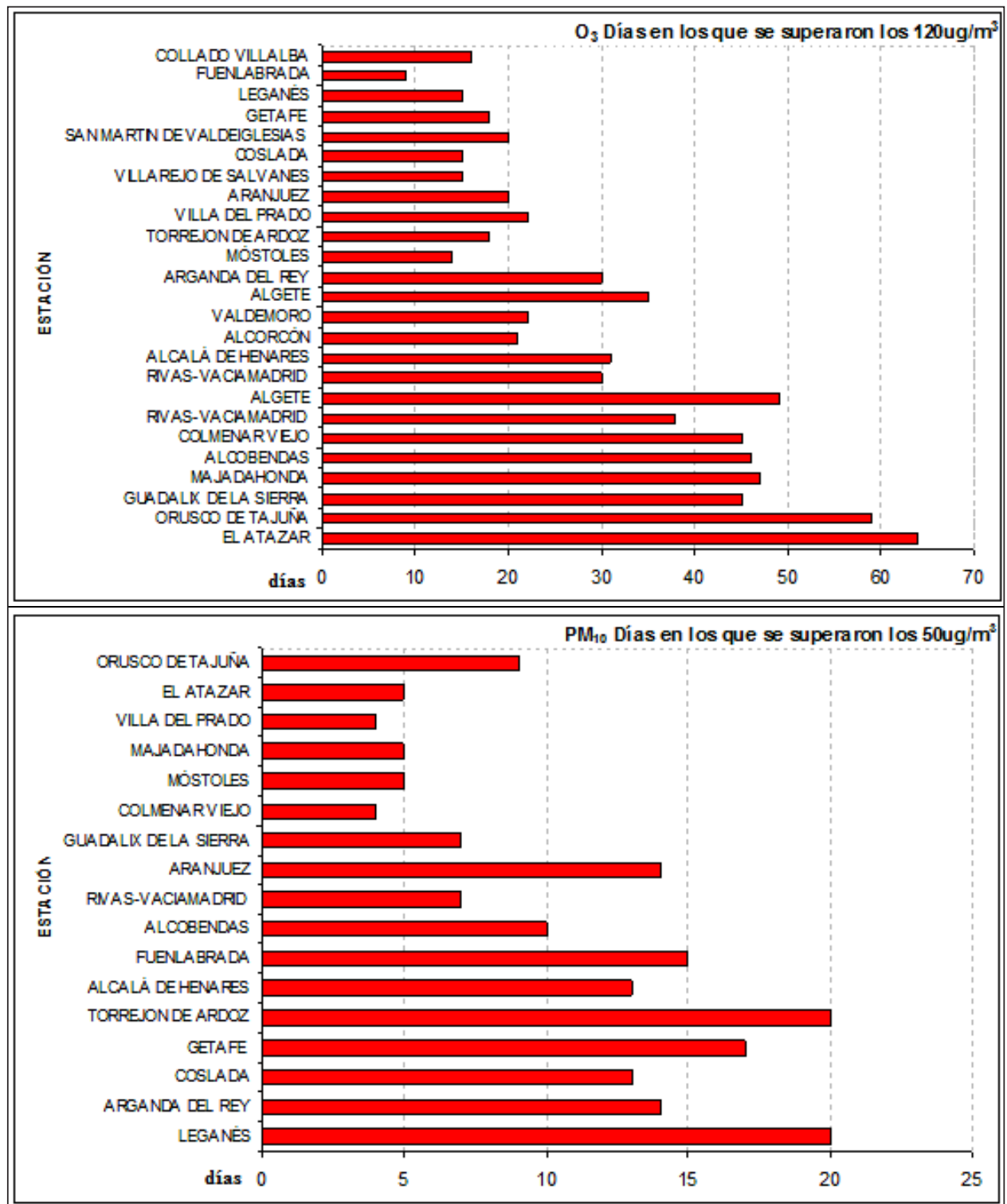

Fuente: Elaboración propia, a partir de Comunidad de Madrid (2017). 
Toda esta situación supone un mayor impacto en el medio geográfico cuando se trata de analizar la situación de grandes urbes, como es el caso de la ciudad de Madrid, donde los riesgos se incrementan y los daños se acentúan, para una sociedad que no es consciente de su vulnerabilidad a la hora de respirar un aire contaminados, insano que merma su calidad y esperanza de vida. Detengámonos en su análisis.

\section{EL AIRE DEGRADADO DE LA CIUDAD DE MADRID: REPERCUSIONES SOBRE UNA ACTIVIDAD EN ALZA, EL TURISMO}

Al igual que sucede en el conjunto de la Comunidad, la ciudad de Madrid cuenta con un entramado de redes de medición de las emisiones de sustancias contaminantes en su territorio. En los momentos actuales, tras acometer una remodelación y reorganización espacial de las estaciones de control de la calidad del aire (llevada a cabo en el año 2009), el municipio de Madrid cuenta con veinticuatro estaciones subdivididas en tres tipologías; nueve estaciones de tráfico -localizadas próximas al trazado viario-, doce estaciones urbanas -próximas a espacios verdes, como parques- y tres estaciones suburbanas -alejadas de los núcleos urbanos-; si bien, como ocurría en la Comunidad de Madrid, no todas toman muestras y recogen datos del conjunto de sustancias contaminantes estipulados en la legislación analizada -a diferencia de la red de medición existente hasta su reorganización-, sino que cada estación evalúa un determinado número de contaminantes. De este modo, del conjunto de sustancias más degradantes, encontramos que el dióxido de nitrógeno $\left(\mathrm{NO}_{2}\right)$ se analiza en todas y cada una de las estaciones de la red, mientras que el Ozono troposférico se recoge en catorce estaciones, las partículas en suspensión $\mathrm{PM}_{10}$ en doce estaciones y las $\mathrm{PM}_{2,5}$ tan solo en seis de las estaciones. Todo ello nos muestra que, en los momentos actuales, no hay un control real y exhaustivo de los riesgos a los que se expone la población de Madrid, ni los daños asociados a la exposición continua y constante a un daño, en la mayoría de los casos, irreparable.

Igualmente, todo este entramado de estaciones de control de la calidad del aire atmosférico, se encuadra entorno a seis zonas, claramente delimitadas, que tiene por objeto la gestión de situaciones de riesgo extremo, en los que se superen los valores límite establecidos por Ley, si bien, volvemos a encontrarnos ante la problemática de que no todas las estaciones recogen datos del conjunto de sustancias contaminantes, por lo que los episodios de riesgo extremo se ven mermados. Además, se debería tener presente que nos encontramos ante una gran aglomeración donde el tráfico rodado es constante, continúo y cada vez mayor, y, por ende, debería existir una red de medición más extensa y, con más estaciones denominadas de "tráfico". Por otra parte, en el caso concreto de Madrid, debemos tener presente que el problema real al que se enfrenta y que no encuentra solución directa en la toma de medidas extremas como las que están acaeciendo en los últimos tiempos ${ }^{13}$, reside en el "Modelo de Desarrollo" y al proceso de expansión de la ciudad de

13 Todo ello, conlleva a la implantación de medidas restrictivas, aparentemente orientadas al control de las emisiones de contaminantes atmosféricos, si bien, debemos tener presente que, con la actual red de medición no se conoce realmente el valor total de las emisiones generadas en Madrid y, además, claro ejemplo de ello lo encontramos en noticias de prensa como la del pasado 20 de septiembre del 2017, en la que todos los periódicos se hacían "eco" de la siguiente noticia: "Carmena cierra el centro a los no residentes en 2018. El Ayuntamiento 
Madrid, el cual supuso crecer hacia el extrarradio, extendiendo los límites territoriales de la urbe hacia zonas rurales a través de la construcción de núcleos de población alrededor de las radiales y, posteriormente, continuar con un proceso especulativo de unión entre los diferentes núcleos urbanos o rurubanos, conectándolos por un nuevo entramado de carreteras. Todo ello generaba y, continúa haciéndolo, una imperiosa necesidad de movilidad constante -por trabajo, estudios y ocio-, de esa población hacia el municipio de Madrid, siendo de imperiosa necesidad -sobre todo, teniendo en cuenta la dualidad espacio vs. tiempo-, del uso del vehículo privado, con independencia de las mejoras del transporte público. Además, a pesar de que en el centro de Madrid no se permitiese el tráfico rodado, no quiere decir que la contaminación desaparezca, puesto que los movimientos de aire en altura y en superficie ayudan al transporte de las sustancias contaminantes al resto de territorio.

retrasa la puesta en marcha de su medida más restrictiva al primer semestre del próximo año. La Gran Vía dejará de ser de paso. En 2025 no podrá circular el 28\% del parque actual” (La Razón); "Cuenta atrás para la puesta en marcha del "plan anticoches" de Carmena. Restricciones de tráfico para el 2018" (El Mundo); o las continuas restricciones de acceso al centro de la capital mediante planes de actuación como "Madrid limita la velocidad en la M-30 y los accesos por contaminación" (El País, 29 de septiembre del 2017). 


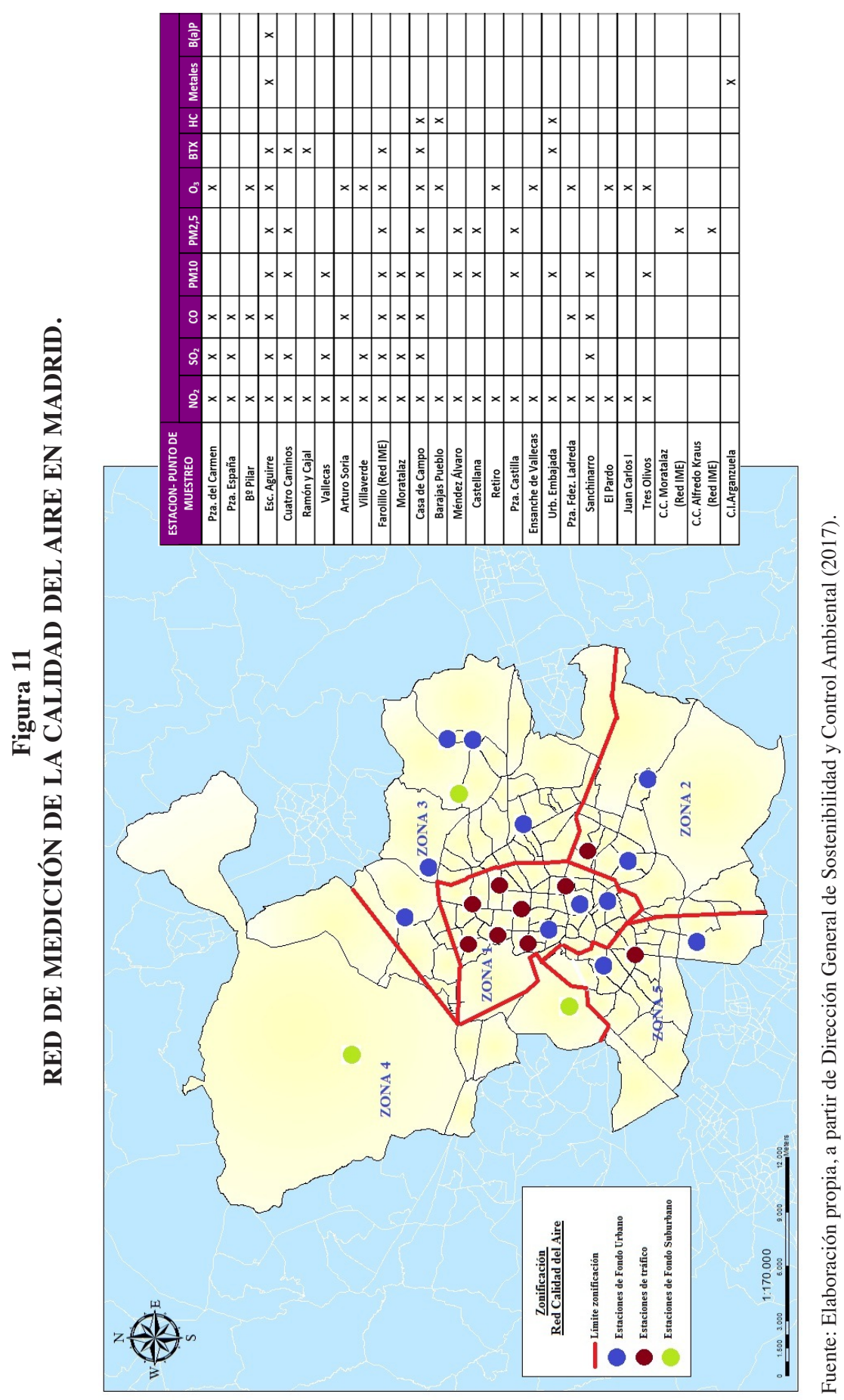


De este modo, si analizamos los riesgos a los que se expone a diario la población de Madrid, podemos observar que la ésta se encuentra expuesta a cantidades muy elevadas de los contaminantes más perjudiciales para la salud humana como son el monóxido de carbono $(\mathrm{CO})$, los óxidos de nitrógeno $(\mathrm{NOx})$, el dióxido de nitrógeno $\left(\mathrm{NO}_{2}\right)$, el ozono troposférico $\left(\mathrm{O}_{3}\right)^{14}$ y las partículas en suspensión $\left(\mathrm{PM}_{10}\right.$ y $\left.\mathrm{PM}_{2,5}\right)$; que, a pesar de haber ido disminuyendo desde 1990 (como podemos ver en las Figuras 11 y 12, adjuntas), continúan estando por encima de los niveles límites de emisión estipulados por la Ley (a excepción del ozono troposférico que ha ido aumentando de manera progresiva y, sobre todo, de forma muy intensa, en los últimos años) y, aún más, los establecidos por la Organización Mundial de la Salud. Todo ello supone un deterioro continuo de la calidad del aire atmosférico a Madrid que, como vimos con anterioridad, se ve agravado por las condiciones climáticas adversas -a tenor de estas circunstancias- que hacen más vulnerable a la población, haciéndola estar en continuo riesgo.

Indiscutiblemente, en el caso concreto de la ciudad de Madrid, el grueso de las emisiones de contaminantes son generadas, junto con las calefacciones, las infraestructuras de ocio, comercio y restauración, por el transporte rodado -aunque durante el periodo de "crisis económica" se redujeron notablemente, debido a la disminución del uso de los vehículos privados, aunque la esta tendencia tendió a invertirse en los últimos cinco años ${ }^{15}$-, que intensifican y agravan las enfermedades de carácter respiratorio, cardiovascular, circulatorio, aparición de cánceres y, en muchos casos, la muerte prematura.

Por su parte, en cuanto al dióxido de azufre, tal y como expone el profesor Felipe Fernández García “hasta hace unos era el contaminante más utilizado como representativo de la calidad del aire en las ciudades, en la actualidad y especialmente en los países desarrollados, (...) han determinado una importante reducción lo que podría ser interpretado como una mejora sustancial en la calidad del aire".

14 Los mecanismos de formación del ozono explican que las concentraciones de este contaminante sigan un ciclo diario y anual con máximos en las horas centrales de! día y en los meses cálidos, en estrecha relación con las variaciones diarias y estacionales de la radiación solar. El smog fotoquímico, por tanto, sigue un ritmo diferente al producido por el $\mathrm{SO}_{2}$, cuyos máximos son invernales relacionados con la mayor actividad de las emisiones procedentes de las calderas de calefacción y el predominio de situaciones anticiclónicas con inversiones térmicas en superficie (Fernández García, F. 1995). En el caso de Madrid, las máximas concentraciones de ozono corresponden a los meses estivales coincidiendo con la máxima actividad solar; espacialmente se observa que en las áreas periféricas se registran sistemáticamente valores superiores a los de la ciudad, con máximos muy destacados en los núcleos situados al norte de Madrid coincidiendo con su posición a sotavento en relación a los vientos dominantes, que en nuestra región son del SW.

15 Tal y como se recoge en el Informe sobre el Estado de la Movilidad de la Ciudad de Madrid (2015): "Desde 2004 el transporte público interurbano ha caído más de un 18\%, mientras el tráfico en los accesos a Madrid se ha mantenido casi estable (-2\%). Entre 2013 y 2014 el tráfico de vehículos en los accesos a Madrid ha aumentado un $1,1 \%$, aunque los desplazamientos en cercanías y autobuses interurbanos han descendido un $0,6 \%$. 
Figura 12

CONCENTRACIÓN MEDIA ANUAL DE EMISIONES CONTAMINANTES ATMOSFÉRICOS (I)
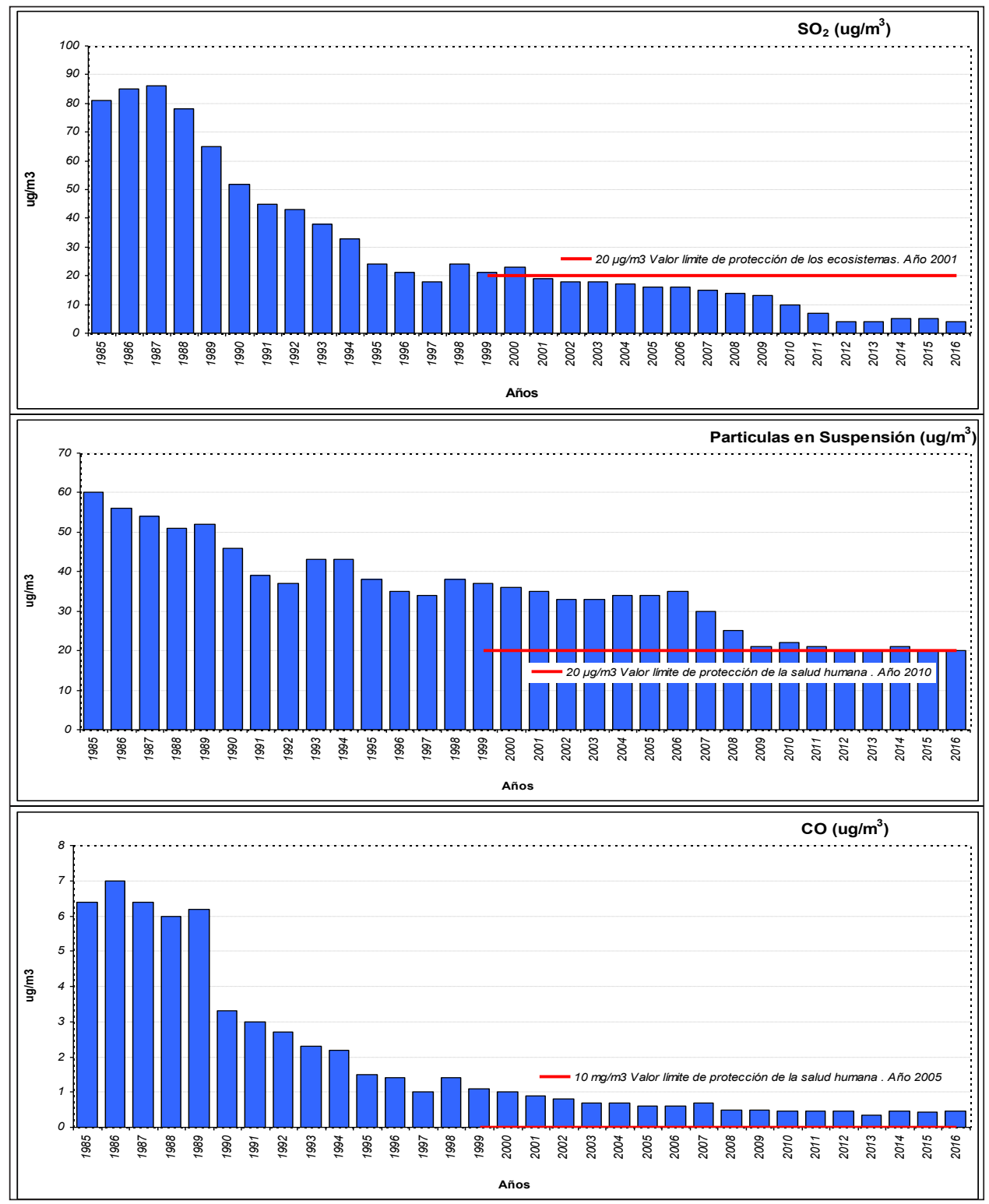

Fuente: Elaboración propia, a partir de la información obtenida del Ayuntamiento de Madrid y www.madrid.org. 
Figura 13

CONCENTRACIÓN MEDIA ANUAL DE EMISIONES CONTAMINANTES ATMOSFÉRICOS (II)
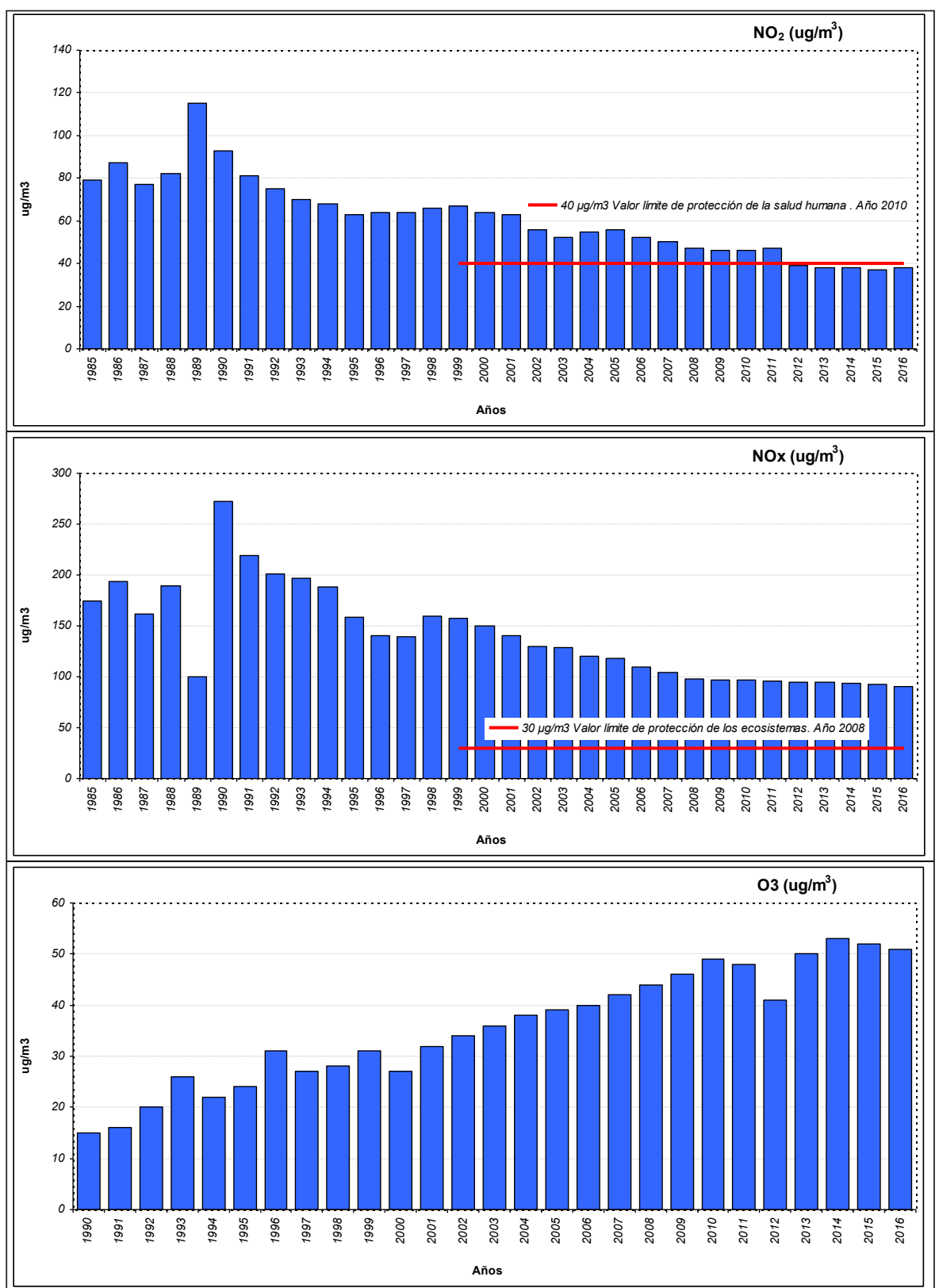

Fuente: Elaboración propia, a partir de la información obtenida del Ayuntamiento de Madrid y www.madrid.org. 
En cuanto las emisiones de metano observamos un aumento notable en el 2016 respecto a 1990, a pesar de sufrir continuos altibajos en los últimos años. Esta es una cuestión relevante pues, el $\mathrm{CH}_{4}$ es treinta y cuatro veces más contaminante que el $\mathrm{CO}_{2}$ y genera elevados riesgos emanados de la elevación de la temperatura y de los cambios de composición del aire que genera sustanciales modificaciones en la atmósfera (a causa de la combustión de biomasa en calderas y vehículos, principalmente), que provocan alteraciones metabólicas, problemas respiratorios, daños cardiacos y, el denominado efecto invernadero. En contraposición, encontramos las emisiones de Hidrocarburos que, a pesar de haberse reducido de manera importante en el año 2012 en comparación con 1990, se ha visto incrementado de nuevo, en los últimos cuatro años, lo que provoca riesgos en la salud humana, sobre todo afecta al sistema respiratorio, al sistema nervioso, problemas de piel y de coagulación, daños en el sistema inmunitario -reduciendo el número de plaquetas y leucocitos, y, en algunos casos provocar cáncer.

\section{Figura 14 \\ CONCENTRACIÓN MEDIA ANUAL DE EMISIONES CONTAMINANTES ATMOSFÉRICOS (III)}

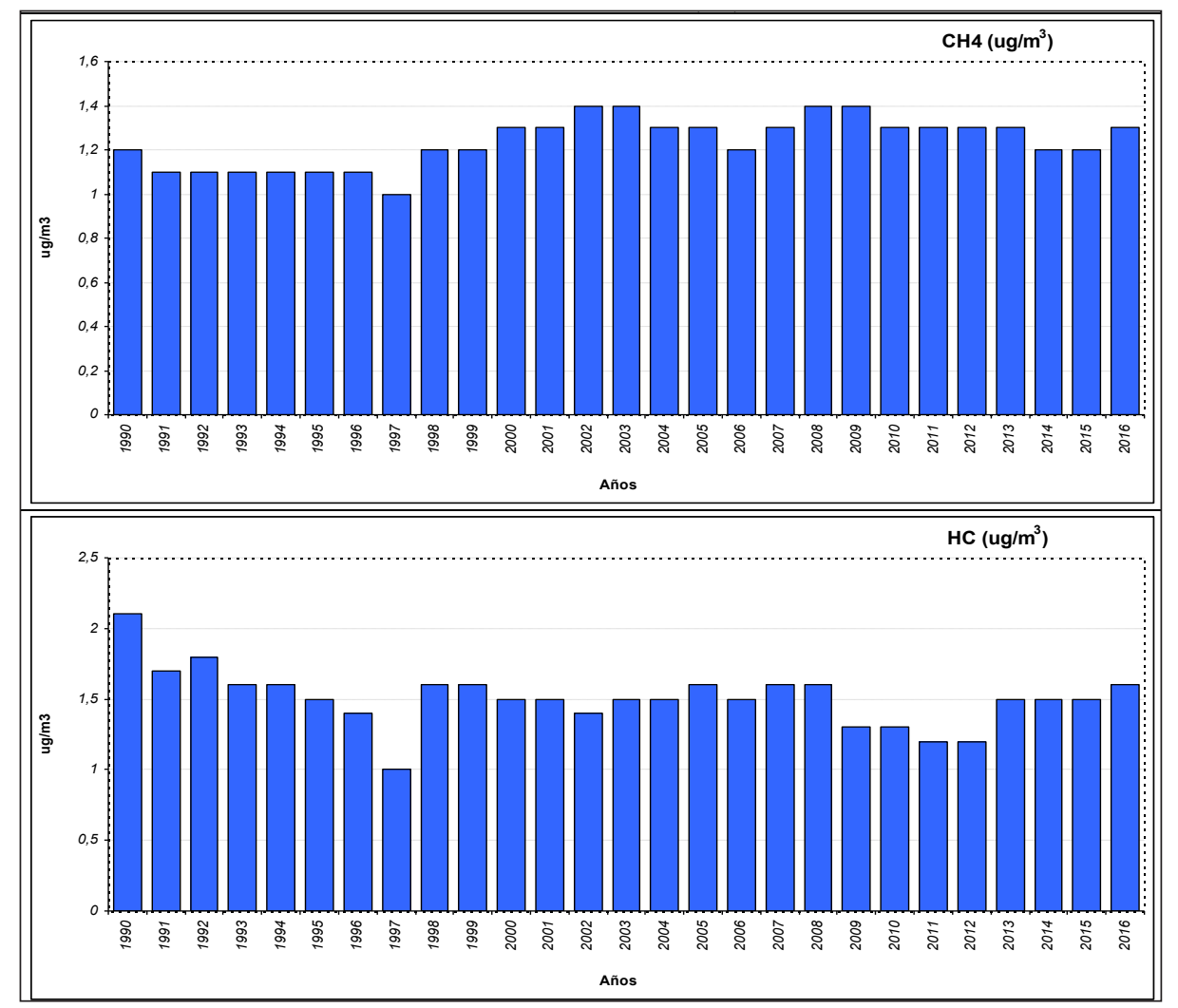

Fuente: Elaboración propia, a partir de la información obtenida del Ayuntamiento de Madrid y www.madrid.org. 


\section{Figura 15 \\ EMISIONES DE GASES EFECTO INVERNADERO EN EL MUNICIPIO DE MADRID (1999 Y 2014) ${ }^{16}$}
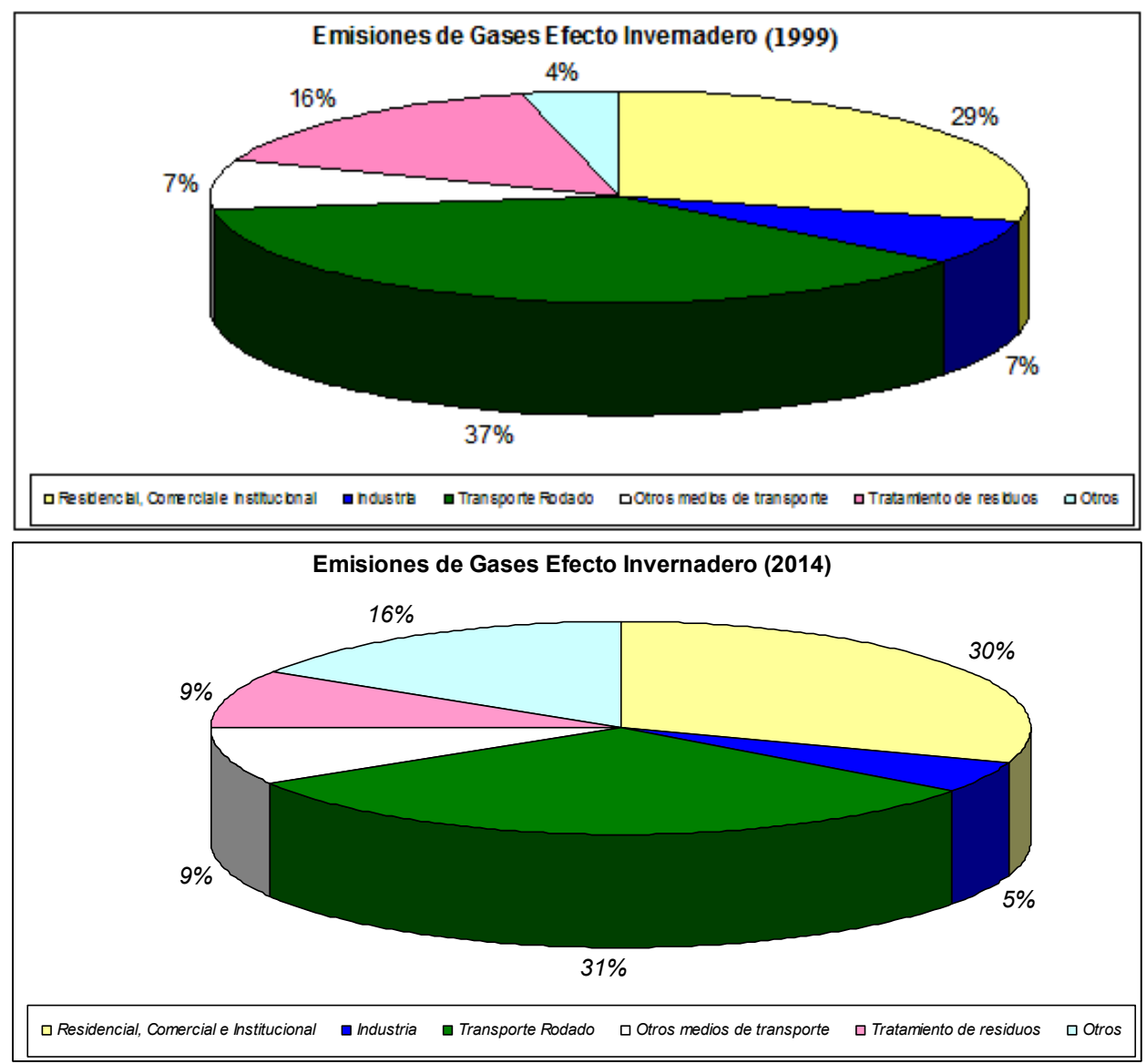

Fuente: Elaboración propia, a partir del Inventario de Emisiones de Contaminantes a la Atmósfera en el Municipio de Madrid (2016).

Por otra parte, al analizar las emisiones de Gases Efecto Invernadero en la ciudad de Madrid (ver Figura 15), observamos que la principal fuente de contaminación se encuentra en el transporte rodado, a pesar de haber reducido el porcentaje de emisión -en pro de otras fuentes de contaminación-, continúa teniendo un elevado nivel de degradación ambiental. Esto sustenta la primigenia idea determinada anteriormente, en la que se exponía la necesidad de aumentar el número de estaciones de "tráfico", en contraposición a las de "fondo urbano". Indiscutiblemente, una redución del 6\% en el total de las emisiones procedentes del

16 Emisiones de Gases Efecto Invernadero por sectores (*) No se incluyen las absorciones de $\mathrm{CO}_{2}$ de la naturaleza. 
tráfico rodado supone una notable mejoría respecto a la situación existente en 1999, si bien, aún supone un peso muy elevado respecto del total; indiscutiblemente, gran parte de este "logro" es consecuencia de la modernización de la flota de automóviles, los mayores controles llevados a cabo en los vehículos en circulación, y, en parte, a la "crisis económica" que redujo considerablemente la movilidad en la urbe madrileña durante bastantes años. Además, debemos señalar que las fuentes de emisión por tratamiento de residuos también presentan una sustancial reducción en el año 2016 frente a 1999 (disminuyó del 16\% al 9\%), consecuencia de la relocalización de las plantas de reciclaje y la mejora en sus infraestructuras.

\section{A MODO DE CONCLUSIONES}

Tras lo anteriormente expuesto, podemos concluir que la contaminación atmosférica en la Comunidad de Madrid representa un claro ejemplo de riesgo antrópico -con implicaciones notables sobre las actividades turísticas-, que se ve potenciado, transformado y modificado por las condiciones climáticas ${ }^{17}$, puesto que en su formación intervienen de manera conjunta las fuentes de emisión como el ámbito receptor que es la atmósfera, convirtiéndose en un elemento más que influye en los procesos de concentración de los contaminantes en lugares cercanos o próximos a los focos de emisión en determinadas condiciones climáticas (debemos tener presente que las cantidades de emisión generadas en la Comunidad de Madrid varían "relativamente poco" a lo largo del año durante el día, pero siempre existen momentos en los que se producen episodios de alerta por superación de los niveles máximos y, esto es consecuencia de las condiciones temporales de estabilidad atmosférica -de carácter anticiclónica-, y un aire estático "carente" de movimiento; puesto que en épocas de inestabilidad atmosférica en las que existen rachas de viento, los contaminantes no pueden concentrarse en un determinado lugar, sino que son transportados a largas distancia, favoreciendo la disminución de los niveles de riesgo en las áreas próximas a los focos de emisión.

No obstante, debemos tener en cuenta que, aunque a corto plazo, el riesgo tiende a ser menos en circunstancia de inestabilidad atmosférica y viento, eso no quiere decir que los riesgos sean erradicados; a medio y, sobre todo, a largo plazo, producen cambios en la propia atmósfera que, en teoría, podrían acarrear condiciones de cambio en el clima, a causa de su efecto potenciador del efecto invernadero natural o provocar episodios de lluvia ácida.

De este modo, puesto que el objetivo general es proteger, conservar y reparar la calidad atmosférica como esencia fundamental de mejorar y potenciar la calidad de vida en nuestras ciudades, entendidas estas como un sistema complejo, se deben plantear estrategias orientadas a la interacción de los sistemas urbanos y otros sistemas circundantes, con el fin de mejorar la calidad de vida de la población y, sobre todo, favoreciendo los procesos de desarrollo sostenible. Con ello, lo primordial no es solo reducir los niveles de emisión producidos por el transporte rodado o minimizar el conjunto de emisiones contaminantes,

17 Ejemplo de ello lo encontramos en el trabajo del profesor Felipe Fernández García sobre "La contaminación atmosférica como factor de riesgo: El caso de Madrid,1996”. 
sino favorecer la creación y la puesta en funcionamiento de planes de ordenación urbana sostenibles y sostenidas en el tiempo.

Por otra parte, señalar que mientras que, los usos residenciales y comerciales han tendido a incrementar sus emisiones, al igual que otros tipos de transporte -principalmente, el ferrocarril-, aunque no tuvieron una relevancia sustancial en comparación con otros tipos de fuentes de emisión que se incrementaron del $4 \%$ al $16 \%$, procedentes de productos de consumo -limpieza, pintura, jardinería,...-, y derivados de la construcción, entre otros. Lo que modifica, no sólo los hábitos de consumo sino los modelos de organización y desarrollo territorial, marcando nuevos procesos de producción, distribución y consumo, en un espacio complejo, diversos y en continuo cambio, como es la ciudad de Madrid. Por lo que existe una necesidad real y urgente de implementar medidas de protección y conservación de la atmosfera en el conjunto de la Comunidad de Madrid, ampliando la Red de Medición al conjunto regional y potenciando estudios que analicen las condiciones adversas y los riesgos a los que se expone, tanto la población, como el resto de diversidad biológica -vegetación y fauna- de los ecosistemas de la Comunidad de Madrid.

Así, pues, nos encontramos que en Madrid, con el fin de proteger y cuidar las actividades relacionadas con el turismo, existe una necesidad real y urgente de generar medidas de protección y conservación de la atmósfera, en el conjunto de la Comunidad, en general, y en la ciudad de Madrid, en particular, ampliando la Red de Medición, así como realizando nuevos estudios que analicen las condiciones adversas y los riesgos a los que se exponen, la diversidad biológica, y la población que habita en nuestro territorio, así como el conjunto de las actividades turísticas que en él se desarrollan.

\section{BIBLIOGRAFÍA}

ANTON CLAVÉ, S., RULLAN SALAMANCA, O. y VERA REBOLLO, J.F. (2011): "Mass Tourism Development on the Mediterranean Coast", Tourism Geographies, vol. 13 (3), pp. 495-501.

AYUNTAMIENTO DE MADRID (2015): Estado de la Movilidad de la Ciudad de Madrid (2014), 43 pp.

AYUNTAMIENTO DE MADRID (2018): Inventario de Emisiones de Contaminantes a la Atmósfera en el Municipio de Madrid (1999-2016), 56 pp.

BORRELL MERLIN, M.D. (2005): «Turismo, medioambiente y desarrollo sostenible en el Mediterráneo», Observatorio Medioambiental, vol. 8, pp. 305-330.

BUCKELY, R. (2012): "Sustainable tourism: research and reality", Annals of Tourism Research, vol. 39 (2), pp. 528-546.

BUHALIS, D. (2000): «Marketing the competitive destination of the future», Tourism Management, vol. 21 (1), pp. 97-116.

CALVO GARCÍA-TORNEL, F. (1984): "La Geografía de los riesgos”. Barcelona. Geocrítica, Año IX, n ${ }^{\circ} 54$.

COMUNIDAD DE MADRID (2016): Estrategia de calidad del aire y cambio climático de la Comunidad de Madrid 2013-2020. Plan Azul+.

COMUNIDAD DE MADRID (2016): Plan de Mejora de la calidad del aire en el Corredor del Henares. 
COMUNIDAD DE MADRID (2017): Inventario de Emisiones a la Atmósfera en la Comunidad de Madrid. Plan Azul+.

DIAZ-DE-QUIJANO, M. et al. (2009): “Increasing interannual and altitudinal ozone mixing ratios in the Catalan Pyrenees". Atmospheric Environment vol. 43 (38), pp. 6.049-6.057.

DIRECCIÓN GENERAL DE MEDIO AMBIENTE DE LA COMUNIDAD DE MADRID (2017): Estadísticos 2016 del Ministerio.

ESPEJO MARÍN, C. y GARCÍA MARÍN, R. (2017): “Caso 3. La planificación del turismo en áreas rurales”, en Simancas Cruz, M.R. (Coord.) La planificación y gestión territorial del turismo, Madrid, Síntesis, pp. 229-258.

ELIAS, J. (1998): “Control de la contaminación atmosférica”, en AA.VV. (1998) Enciclopedia de salud y seguridad en el trabajo. Oficina Internacional del Trabajo.

EL MUNDO (3 de septiembre del 2017): "Cuenta atrás para la puesta en marcha del "plan anticoches" de Carmena. Restricciones de tráfico para el 2018". Ver enlace web: https:// www.elmundo.es/madrid/2017/09/03/59aae78aca474199208b4609.html

EL PAÍS (29 de septiembre del 2017): "Madrid limita la velocidad en la M-30 y los accesos por contaminación”. Ver enlace web: https:/elpais.com/ccaa/2017/09/29/ madrid/1506636503_511615.html

FERNÁNDEZ GARCÍA, F. (1996): "La contaminación atmosférica como factor de riesgo: El caso de Madrid", Territorium, no 3, pp.15-24.

GARCÍA-GÓMEZ, H. el al. (2014): "Nitrogen deposition in Spain: modeled patterns and threatened habitats within the Natura 2000 network". Science of the Total Environment, vol. 485, pp. 450-460.

JENKINS, J.M., HALL, C.M. y MKNO, M. (2014): “Tourism and Public Policy: Contemporary Debates and Future Directions", en The Wiley Blackwell Companion to Tourism. Chichester, John Wiley \& Sons, pp. 542-555.

JIMÉNEZ HERRERO, L.M. (2007): "Hacia la sostenibilidad turística en España”, Estudios Turisticos, $\mathrm{n}^{\circ}$ 172-173, pp. 73-79.

LA RAZÓN (19 de septiembre del 2017): “Carmena cierra el centro a los no residentes en 2018”. Ver enlace web: https://www.larazon.es/local/madrid/carmena-cierra-el-centroa-los-no-residentes-en-2018-MD16046138

OBSERVATORIO DE LA SOSTENIBILIDAD EN ESPAÑA (2008): Calidad del aire en las ciudades españolas, clave de sostenibilidad urbana, $382 \mathrm{pp}$.

OCHOA-HUESO, R. et al. (2017): "Ecological impacts of atmospheric pollution and interactions withclimate change in terrestrial ecosystems of the Mediterranean Basin: Current research and future directions", Environmental pollution, vol. 227, pp. 194-206.

OLCINA CANTOS, J. et al. (2014): “Turismo, cambio climático y agua: escenarios de adaptación en la costa mediterránea española”, en Libro Jubilar en Homenaje al profesor Antonio Gil Olcina, Alicante, Servicio de Publicaciones de la Universidad de Alicante, pp. 171-193.

OLCINA CANTOS, J, y MIRÓ-PÉREZ, J.J. (2016). “El clima, recurso básico del turismo alicantino. De la valoración del clima invernal al aprovechamiento intensivo del clima estival", Canelobre, $\mathrm{n}^{\circ}$ 66. Alicante, Instituto Alicantino de Cultura Juan Gil-Albert. Pp. 19-37. 
PULIDO FERNÁNDEZ, J.I. y LÓPEZ SÁNCHEZ, Y. (2013): "Propuesta de contenidos para una política turística sostenible en España", Pasos. Revista de Turismo y Patrimonio Cultural, $\mathrm{n}^{\circ} 11$, pp. 525-546.

PULIDO FERNÁNDEZ, J.I. y PULIDO FERNÁNDEZ, M.C. (2015): “¿Sigue vigente el paradigma del turismo sostenible? Reflexiones a la luz de la literatura reciente", Pasos. Revista de Turismo y Patrimonio Cultural, $\mathrm{n}^{\circ}$ 13, pp. 1.315-1.335.

SANTOS-LACUEVA, R., ANTON CLAVÉ, S y SALADIÉ, O (2017): "Discontinuidades y limitaciones de los últimos planes turísticos de España en relación a la sostenibilidad ambiental del turismo de sol y playa", Cuadernos de Turismo, $\mathrm{n}^{\circ} 40$, pp. 599-626

SIMPSON, D. et al. (2014): "Impacts of climate and emission changes on nitrogen deposition in Europe: a multi-model study", Atmospheric Chemistry and Physics, vol. 14 (13), pp. 6.995-7.017.

SOTELO NAVALPOTRO, J.A. (2007): Medio Ambiente, Desarrollo y Sostenibilidad; Modelos y políticas de actuación contradictorias. Oxford University Press, 428 pp.

SOTELO NAVALPOTRO, J.A. et al. (2015): "Territorio y sostenibilidad: Algunos problemas medioambientales en España (I)", M+A Revista Electrónica de Medio Ambiente, vol. 16 (1), pp. 45-79.

SOTELO NAVALPOTRO, J.A. y SOTELO PÉREZ, M. (2018): “Turismo y riesgos naturales en las "Rías Baixas" gallegas. Estudio de caso", Cuadernos de Turismo, $\mathrm{n}^{\circ}$ 42, pp. 481-500.

SOTELO PÉREZ, M. y SOTELO PÉREZ, I. (2017): “Una aproximación al marco teórico de los riesgos", Observatorio Medioambiental, vol. 20, pp. 9-36.

SOTELO PÉREZ, M., SOTELO PÉREZ, I, y SOTELO NAVALPOTRO, J.A. (2017), "Planificación, gestión y protección de la calidad del aire en España", Observatorio Medioambiental, vol. 20, pp. 319-351.

VERA REBOLLO, J.F. e IVARS, J. (2009): "Spread of low-cost carriers: tourism and regional policy effects in Spain", Regional Studies, vol. 43 (3), pp. 559-570. 
